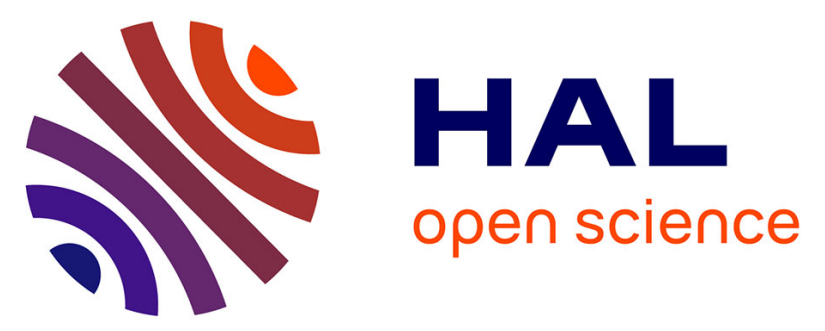

\title{
Uppermost mantle velocity beneath the Mid-Atlantic Ridge and transform faults in the equatorial Atlantic Ocean
}

\author{
Guilherme Weber Sampaio de Melo, Ross Parnell-Turner, Robert Dziak, \\ Deborah Smith, Marcia Maia, Jean-Yves Royer
}

\section{To cite this version:}

Guilherme Weber Sampaio de Melo, Ross Parnell-Turner, Robert Dziak, Deborah Smith, Marcia Maia, et al.. Uppermost mantle velocity beneath the Mid-Atlantic Ridge and transform faults in the equatorial Atlantic Ocean. Bulletin of the Seismological Society of America, 2020, 111 (2), pp.10671079. hal-03062624

\section{HAL Id: hal-03062624 https://hal.science/hal-03062624}

Submitted on 14 Dec 2020

HAL is a multi-disciplinary open access archive for the deposit and dissemination of scientific research documents, whether they are published or not. The documents may come from teaching and research institutions in France or abroad, or from public or private research centers.
L'archive ouverte pluridisciplinaire HAL, est destinée au dépôt et à la diffusion de documents scientifiques de niveau recherche, publiés ou non, émanant des établissements d'enseignement et de recherche français ou étrangers, des laboratoires publics ou privés. 


\title{
Bulletin of the Seismological Society of America \\ Uppermost mantle velocity beneath the Mid-Atlantic Ridge and transform faults in the equatorial Atlantic Ocean \\ --Manuscript Draft--
}

\begin{tabular}{|c|c|}
\hline Manuscript Number: & BSSA-D-20-00248R5 \\
\hline Section/Category: & Regular Issue \\
\hline Full Title: & $\begin{array}{l}\text { Uppermost mantle velocity beneath the Mid-Atlantic Ridge and transform faults in the } \\
\text { equatorial Atlantic Ocean }\end{array}$ \\
\hline Corresponding Author's Institution: & Federal University of Rio Grande do Norte \\
\hline Corresponding Author E-Mail: & gwsmelo@ufrn.edu.br \\
\hline \multirow[t]{5}{*}{ Order of Authors: } & Guilherme Weber Sampaio de Melo, M.D. \\
\hline & Deborah K. Smith \\
\hline & Marcia Maia \\
\hline & Aderson F. do Nascimento \\
\hline & Jean-Yves Royer \\
\hline Abstract: & 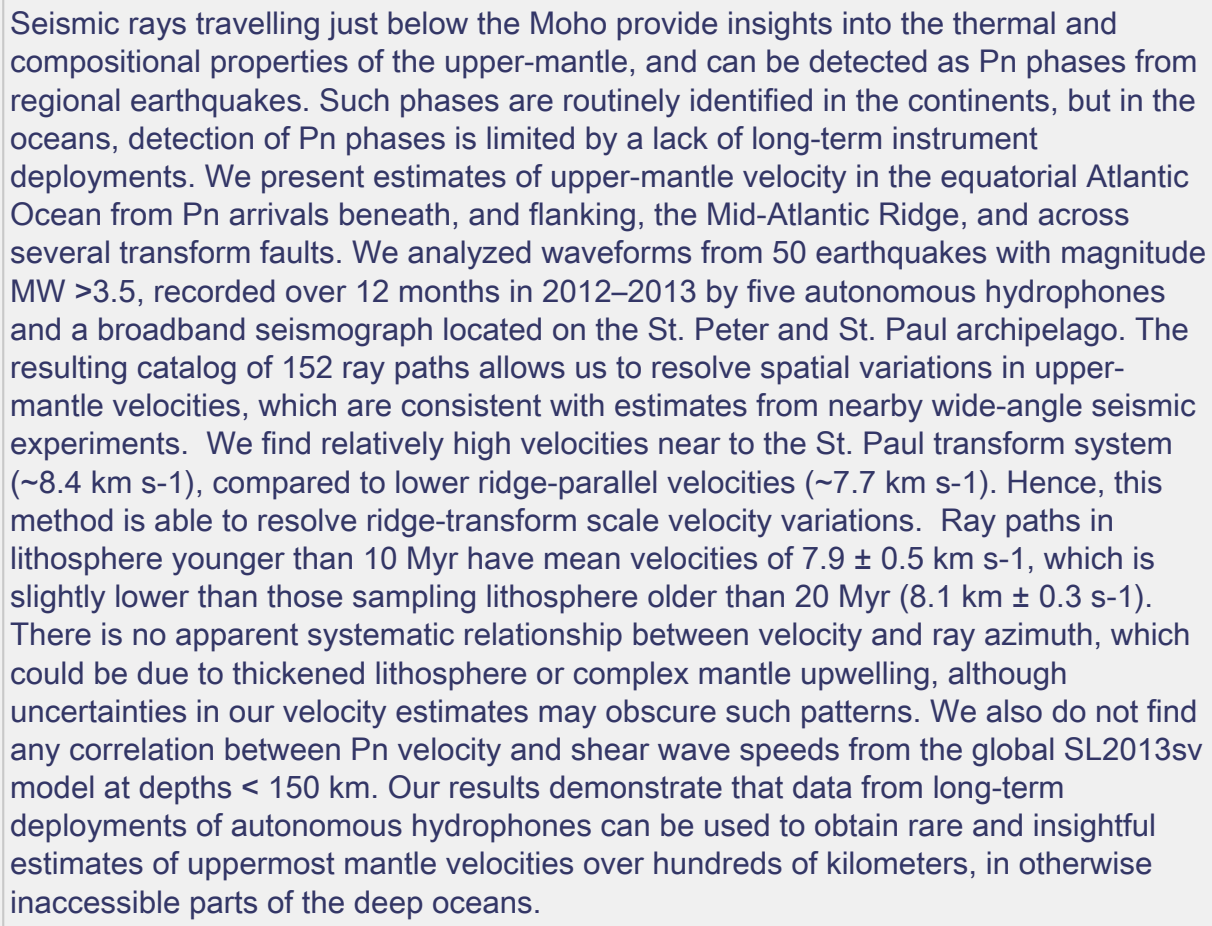 \\
\hline
\end{tabular}

Author Comments:

Suggested Reviewers:

\author{
Rachel Abercrombie \\ Boston University \\ rea@bu.edu \\ Seismology expert with interests in equatorial Atlantic \\ Emilie Hooft
}




\begin{tabular}{|c|c|}
\hline & $\begin{array}{l}\text { University of Oregon } \\
\text { emilie@uoregon.edu } \\
\text { Seismology expert with interests in upper mantle structure }\end{array}$ \\
\hline & $\begin{array}{l}\text { John Collins } \\
\text { Woods Hole Oceanographic Institution } \\
\text { jcollins@whoi.edu } \\
\text { Seismology expert with interest in passive methods }\end{array}$ \\
\hline \multicolumn{2}{|l|}{ Opposed Reviewers: } \\
\hline \multicolumn{2}{|l|}{ Response to Reviewers: } \\
\hline \multicolumn{2}{|l|}{ Additional Information: } \\
\hline Question & Response \\
\hline $\begin{array}{l}<b>\text { Key Point \#1: }</ b><b r><i>\text { Three key } \\
\text { points will be printed at the front of your } \\
\text { manuscript so readers can get a quick } \\
\text { overview. Please provide three } \\
\text { COMPLETE sentences addressing the } \\
\text { following: 1) state the problem you are } \\
\text { addressing in a FULL sentence; } 2 \text { ) state } \\
\text { your main conclusion(s) in a FULL } \\
\text { sentence; and } 3 \text { ) state the broader } \\
\text { implications of your findings in a FULL } \\
\text { sentence. Each point must be } 110 \\
\text { characters or less (including spaces). }\end{array}$ & $\begin{array}{l}\text { Upper mantle velocity structure is important, but difficult and expensive to measure in } \\
\text { remote ocean basins }\end{array}$ \\
\hline Key Point \#2: & $\begin{array}{l}\text { Pn arrivals detected by autonomous hydrophones constrain upper mantle velocity in } \\
\text { equatorial Atlantic Ocean }\end{array}$ \\
\hline Key Point \#3: & $\begin{array}{l}\text { No azimuthal dependence of VPn, could be due to thickened lithosphere, or complex } \\
\text { mantle upwelling }\end{array}$ \\
\hline
\end{tabular}


Peter and St. Paul Archipelago islets, where is installed the ASPSP station. Image_credit: Arcero PROARQUIPELAGO
Click here to access/download;Cover Image (photograph to be considered for the cover of BSSA);Acervo

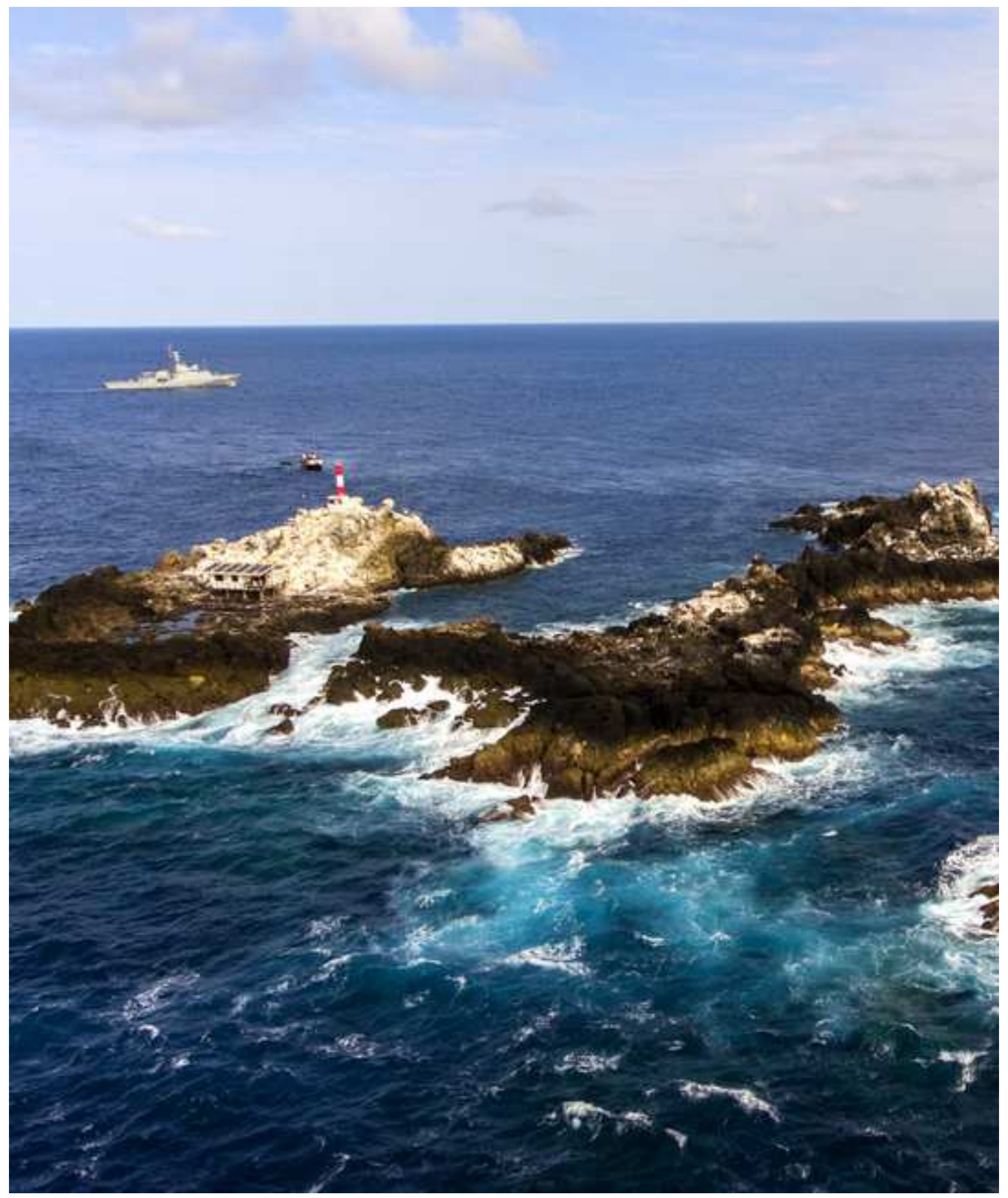


Uppermost mantle velocity beneath the Mid-Atlantic Ridge and transform

\section{faults in the equatorial Atlantic Ocean}

Guilherme W. S. de Melo, Ross Parnell-Turner, Robert P. Dziak, Deborah K. Smith, Marcia Maia, Aderson F. do Nascimento, and Jean-Yves Royer

\section{Abstract}

Seismic rays travelling just below the Moho provide insights into the thermal and compositional properties of the upper-mantle, and can be detected as $P n$ phases from regional earthquakes. Such phases are routinely identified in the continents, but in the oceans, detection of $P n$ phases is limited by a lack of long-term instrument deployments. We present estimates of upper-mantle velocity in the equatorial Atlantic Ocean from Pn arrivals beneath, and flanking, the MidAtlantic Ridge, and across several transform faults. We analyzed waveforms from 50 earthquakes with magnitude $\mathrm{M}_{\mathrm{w}}>3.5$, recorded over 12 months in 2012-2013 by five autonomous hydrophones and a broadband seismograph located on the St. Peter and St. Paul archipelago. The resulting catalog of 152 ray paths allows us to resolve spatial variations in upper-mantle velocities, which are consistent with estimates from nearby wide-angle seismic experiments. We find relatively high velocities near to the St. Paul transform system $\left(\sim 8.4 \mathrm{~km} \mathrm{~s}^{-}\right.$ $\left.{ }^{1}\right)$, compared to lower ridge-parallel velocities $\left(\sim 7.7 \mathrm{~km} \mathrm{~s}^{-1}\right)$. Hence, this method is able to resolve ridge-transform scale velocity variations. Ray paths in lithosphere younger than $10 \mathrm{Myr}$ have mean velocities of $7.9 \pm 0.5 \mathrm{~km} \mathrm{~s}^{-1}$, which is slightly lower than those sampling lithosphere older than $20 \mathrm{Myr}\left(8.1 \mathrm{~km} \pm 0.3 \mathrm{~s}^{-1}\right)$. There is no apparent systematic relationship between velocity and ray azimuth, which could be due to thickened lithosphere or complex mantle upwelling, although uncertainties in our velocity estimates may obscure such patterns. We also 
24 do not find any correlation between $P n$ velocity and shear wave speeds from the global

25 SL2013sv model at depths $<150 \mathrm{~km}$. Our results demonstrate that data from long-term

26 deployments of autonomous hydrophones can be used to obtain rare and insightful estimates of

27 uppermost mantle velocities over hundreds of kilometers, in otherwise inaccessible parts of the 28 deep oceans.

Introduction

31 Seismic velocity measurements provide a useful tool for investigating spatial variations in upper-

32 mantle properties, such as temperature and anisotropy, with implications for melt supply and

33 mantle heterogeneity (e.g. Lin and Phipps Morgan, 1992; Dunn et al., 2005). These

34 measurements are relatively straightforward to obtain on the continents (e.g. Chulick and

35 Mooney, 2002; Chulick et al., 2013). However, it remains challenging and expensive to measure

36 upper-mantle seismic velocity in the deep ocean, due to its remote location and difficulties in

37 deploying long-term instruments on the seafloor. $P n$ phases are rays that are critically refracted

38 at the Moho and propagate along the top of the uppermost mantle (e.g. Linehan, 1940;

39 Brandsdottir and Menke, 1997). At the Mid-Atlantic Ridge (MAR) from $10^{\circ} \mathrm{N}$ to $35^{\circ} \mathrm{N}, \mathrm{Pn}$

40 arrivals from 48 individual ray paths were recorded with hydrophones, and used to investigate

41 upper-mantle velocities, giving a mean velocity of $8.0 \pm 0.1 \mathrm{~km} \mathrm{~s}^{-1}$ (Dziak et al., 2004). This

42 velocity estimate was higher than that from nearby active source seismic experiments along the

43 ridge axis (7.5-7.9 $\mathrm{km} \mathrm{s}^{-1}$; Canales et al., 2000), probably due to the effects of younger and

44 thinner oceanic lithosphere being sampled by the refraction profiles, and the effects of averaging

45 velocities across all rays. Despite such advances, upper-mantle velocities in the deep oceans

46 remain poorly constrained, and the potential for hydrophone-recorded $P n$ phases to resolve 
47 spatial variations in upper-mantle velocity has not yet been sufficiently tested.

48 Here, we use $P n$ arrivals from regional earthquakes to constrain upper-mantle velocity in

49 the equatorial Atlantic Ocean. Arrivals were recorded by a combination of five moored

50 hydrophones and a single seismograph station installed on the St. Peter and St. Paul islets, giving

51152 ray paths that sample mantle conditions both on- and off-axis, and across the St. Paul

52 transform system. Our study is coincident with several mantle velocity estimates from a wide-

53 angle seismic experiment (Le Pichon et al., 1965), and hence has the opportunity to validate

54 spatial variations in velocity revealed by groups of similar ray paths.

55

56

57

58

59

60

61

62

\section{Equatorial Atlantic Ocean}

In the equatorial Atlantic Ocean $\left(10^{\circ} \mathrm{N}-5^{\circ} \mathrm{S}\right.$ and $\left.34^{\circ} \mathrm{W}-21^{\circ} \mathrm{W}\right)$, the MAR is offset by some of the longest transform faults on Earth, including the Strakhov, St. Paul, and Romanche transforms (Figure 1). The St. Paul transform system consists of four transform faults and three intra-transform ridge segments that accommodate an offset of $630 \mathrm{~km}$. The northwest transform fault is currently undergoing transpression, giving rise to the $\sim 200 \mathrm{~km}$-long and $\sim 30 \mathrm{~km}$-wide Atobá ridge (Maia et al., 2016), and also uplift of $1.5 \mathrm{~mm} \mathrm{yr}^{-1}$ at the St. Peter and St. Paul islets (Campos et al., 2010; Maia et al., 2016). Other transforms in the system do not host topographic highs or an island related to transpression, and hence presumably are not experiencing uplift. In the three intervening spreading segments, seafloor spreading is slow, at $\sim 16 \mathrm{~mm} \mathrm{yr}^{-1}$ average half rate (DeMets et al., 2010). Faulting plays an important role in crustal accretion, and seismicity rates are relatively high, providing a useful tool to investigate the properties of the crust and upper mantle, as well as deformation at long-offset strike-slip systems (e.g. Francis et al., 1978; Abercrombie and Ekstrom, 2001; de Melo and do Nascimento, 2018). 
Methods

71

87 schedules (Figure 1b).

\section{Waveform Data}

We analyzed $P n$ arrivals in waveform data recorded by a combination of five moored autonomous hydrophones and one land-based seismograph (Figure 2). The five autonomous hydrophone instruments were deployed during two separate experiments: stations EA2 and EA8 were part of the Equatorial Atlantic (EA) array (Smith et al., 2012). Data were recorded at 16-bit resolution and a sampling rate of $250 \mathrm{~Hz}$; for further details on these hydrophone instruments see Fox et al. (2001). Hydrophones H2, H4, H5 were deployed during the COLd Mantle Exhumation and Intra-transform Accretion experiment (COLMEIA; Maia et al., 2014, 2016), and recorded data at 24 bit-resolution with a sampling rate of $240 \mathrm{~Hz}$; for further instrument details see D'Eu et al.(2012). We also used waveform data recorded by a three-component broadband seismograph installed at the St. Peter and St. Paul Archipelago Scientific Station on the Belmonte islet (ASPSP; de Melo and do Nascimento, 2018). This station is operated by the Seismological Laboratory of Federal University of Rio Grande do Norte in cooperation with the Brazilian Navy. The sparse distribution and mixed instrument types we used means that data coverage is uneven, as shown in Figure 1b. Waveform data were examined for the time period from July 2012 to July 2013, with recording intervals dictated by technical challenges and vessel

\section{Pn analysis}

Prior to manually picking $P n$ arrivals, we applied a 6-20 Hz Butterworth bandpass filter

91 to the hydrophone data in order to suppress unwanted noise. A bandpass filter with range 4-12

$92 \mathrm{~Hz}$ was applied prior to picking arrivals from the ASPSP seismograph, to suppress additional 
93 microseism noise due to its island location. Based upon origin time, events were manually 94 associated with earthquakes in the International Seismological Center Bulletin (ISC), yielding

95 hypocenter locations, origin times, and magnitudes ranging from 3.5 to $5.4 \mathrm{M}_{\mathrm{w}}$. Earthquakes 96 mostly occur due to strike-slip faulting along the Strakhov, St. Paul, and Romanche transform 97 faults, with additional events due to extension along the intervening spreading ridge segments 98 (Figure 2a). Example arrivals from three events are shown in Figures 3 and 4, highlighting the 99 typical response to strike-slip and normal faulting earthquakes ranging in magnitude from 4.6 to $100 \quad 5.3 \mathrm{Mw}$.

101 Typical $P n$-arrivals are emergent, and have low signal-to-noise ratio (SNR; noted in 102 Figures 3 and 4), making pick identification challenging. Given the mixed nature of our network 103 and often noisy arrivals, picks were made based on the onset of emergent energy combined with 104 changes in SNR, waveform character and amplitude. The observation of linear move-out, 105 consistent with upper mantle velocity, added confidence to our picks, since this moveout is 106 evident across the hydrophone array stations due to wave propagation along the crust-mantle 107 interface (see common-receiver plots in Supplementary Figures S1-S6). $P$-arrivals are easily 108 distinguished from $T$-phase arrivals, which arrive much later than $P$-arrivals, are emergent in 109 character, and are higher in amplitude than $P$-arrivals (see hydrophone H5 in Figure 4). The 110 catalog of detected events is given in Table S1.

111 In order to further test whether the detected arrivals were $P n$ phases, we compared the 112 observed travel times to those predicted by the global iasp91 velocity model (Kennett and

113 Engdahl, 1991). For each source-receiver ray path, we calculated the predicted $P n$ arrival time 114 using iasp91, with the addition of a station-dependent delay to account for the propagation time

115 from seafloor to hydrophone. This delay $(1.2-2.5 \mathrm{~s}$, see Table 1) was estimated using the 
116 hydrophone mooring cable length at each station, and the local water sound velocity estimated

117 from the Global Ocean Sound Speed Profile Library (Barlow, 2019). The predicted $P n$ arrival

118 times differ from the observed $P n$ arrivals by $5-10$ s (Figures 3 and 4), a difference which arises

119 since the iasp91 model contains a crustal layer that is much thicker $(30 \mathrm{~km})$ than that expected in

120 the oceans $(\sim 6 \mathrm{~km})$. Hence, the differences in observed and predicted $P n$ arrival time are

121 probably dominated by this additional crustal layer thickness in the velocity model, plus

122 earthquake location and origin time uncertainties. Although these differences are evident, the

123 waveform character and linear move-out velocity give us confidence in our identification of

124 these emergent phases as $P n$ arrivals.

125 ISC origin times were subtracted from the $P n$ arrival times to obtain travel times for each

126 ray path (i.e. each event-station pair). We account for travel time in the oceanic crust by

127 subtracting ray path distances and travel times for the portion of the path that travels through the

128 crust, assuming that all events occurred at $10 \mathrm{~km}$ depth (ISC catalog), and that crustal thickness

129 is uniformly $6.0 \mathrm{~km}$ with a crustal velocity of $6.5 \mathrm{~km} \mathrm{~s}^{-1}$ (Christeson et al., 2019). For each

130 station, we then calculate the distance and travel time for the portion of the ray path that extends

131 from an earthquake in the crust to the Moho, and back from the Moho to the receiver. Pn velocity

132 is obtained by dividing the distance travelled in the mantle by the travel time in the mantle.

133 Details of these corrections for each station are given in Table 1.

134 Our approach yieldeded $152 P n$ velocity estimates from the catalog of 50 regional

135 earthquakes (Figure 5). Although epicentral distances range from $32 \mathrm{~km}$ to $\sim 1095 \mathrm{~km}$, all 50

136 events were detected at nearly all available stations, implying that the detection threshold of the

137 combined hydrophones and ASPSP station is at least $\mathrm{M}_{\mathrm{w}}$ 3.5. Since most stations were located

138 either near to, or to the north of, the St. Paul fracture zone, our ray path coverage is more 
139 comprehensive in the northern part of the study area. Ray paths sampling upper-mantle

140 velocities to the south of the St. Paul fracture zone are restricted to events detected by

141 hydrophone EA8, and those originating from four earthquakes located at the eastern end of the

142 Romanche transform fault (Figure 5).

\section{Pn velocity uncertainty}

145 The two most significant potential sources of error in our analysis are hypocenter

146 locations of events in the ISC Catalog, and Pn arrival time picks. We estimated hypocenter

147 location (and hence epicentral distance) error to be $\pm 10 \mathrm{~km}$, based upon ISC catalog location

148 and typical error in global earthquake location (Lohman and Simons, 2005; Weston et al., 2012).

149 This hypocenter location error implicitly includes other uncertainties associated with ISC catalog

150 locations, such as those caused by un-modeled three-dimensional velocity structure and picking

151 errors, which result in trade-offs between origin time and location (Bondár and Storchak, 2011).

152 Arrival time pick (and hence also travel time) errors were investigated by estimating SNR for

153 each arrival via two methods, one using the amplitude ratio between peak signal and root mean

154 square noise, and another via the ratio between the short time average amplitude and long time

155 average amplitude (STA/LTA; Figure S7). We find that both SNR estimates are only weakly

156 dependent on epicentral distance and magnitude, however we do observe station-dependent

157 variations in the scatter in SNR. We quantify this scatter in terms of the standard deviation of

158 SNR of arrivals for a particular station (Figure S7e), which likely is due to persistent local noise

159 sources. Hence we estimated arrival time pick error based on the emergent character of arrivals

160 and the standard deviation of SNR, with station-dependent errors defined as $\pm 0.5 \mathrm{~s}$ for EA2 and

161 EA8; $\pm 1.0 \mathrm{~s}$ for $\mathrm{H} 2, \mathrm{H} 4$ and $\mathrm{H} 5$; and $\pm 0.3 \mathrm{~s}$ for ASPSP. 
163 epicentral distance, $d$, and travel time, $t$, have errors that are uncorrelated and random. This

164 assumption is valid since we attribute the main source of travel time error to uncertainty in

165 picking of $P n$ arrivals (which in turn depends on waveform character and noise level), and the

166 distance error is most significantly affected by error in earthquake location from the ISC catalog,

167 which is assumed to be constant and hence is independent from hydrophone Pn pick error. We

168 formally propagate the errors in $d$ and $t$, as follows

$$
\delta v=v \sqrt{\left(\frac{\delta d}{d}\right)^{2}+\left(\frac{\delta t}{t}\right)^{2}}
$$

where $\delta d$ is epicentral distance error, and $\delta t$ is travel time error (e.g. Taylor, 1997). with meter-scale accuracy via the Global Positioning System), there is potential location uncertainty for the moored hydrophones in our network. Moored hydrophone locations were obtained by acoustic triangulation between the mooring acoustic release and the deployment vessel soon after the moorings settled on the seafloor, within error of several meters. In order to account for the possibility of abnormally strong current motion, each instrument was fitted with a pressure and temperature logger below the floatation package, so that any significant hydrophone depth changes would be recorded (e.g. Fox et al., 2001). Significant depth changes were not

179 detected during depolyments, and thus we assume that the hydrophone location was constant 180 during data collection, and hence hydrophone location uncertainty is less than $10 \mathrm{~m}$. 


\section{Results}

\section{Pn velocities}

The resulting $152 P n$ ray paths (Figure 5b) and travel times (Figure 6) indicates uppermantle velocities that vary considerably across the study area, with estimates ranging between 7.2 and $11.1 \mathrm{~km} \mathrm{~s}^{-1}$, and uncertainties ranging from 0.1 to $1.9 \mathrm{~km} \mathrm{~s}^{-1}$ (Table S2). Variability in reduced travel time increases with epicentral distance (Figure 6), although SNR does not show a

191 similar trend (Figure S7). Hence the epicentral distance-dependent scatter in reduced travel time

192 is likely due to variations in the depth of ray penetration (which increases with epicentral

193 distance), and not due to increasing pick uncertainty. At the center of the study area there

194 appears to be a longitudinal variation in $P n$ velocity, with events originating near the St. Paul 195 transform system, and sampling adjacent lithosphere, having higher velocities than those from 196 the adjacent spreading centers (Figure 5a). The best constrained estimate for sub-axis, ridge197 parallel mantle velocity comes from ray paths that sample the portion of the spreading axis 198 between the Strakhov fracture zone and stations near the St. Paul fracture zone (H2, H5 and 199 ASPSP). Here, $P n$ travel times consistently imply relatively low velocities, with a mean of 7.7 $200 \mathrm{~km} \mathrm{~s}^{-1}$. Slightly higher velocities ranging between 7.8 and $8.2 \mathrm{~km} \mathrm{~s}^{-1}$ are indicated by ray paths

201 between hydrophone EA2 and the Strakhov fracture zone, oriented roughly parallel to a plate 202 spreading flowline. Ray paths oriented southwest-northeast (azimuth $\sim 060^{\circ}$ ), i.e. oblique to the 203 spreading direction, between events on the St. Paul fracture zone and detected at hydrophone 204 EA2, have some of the highest mantle velocities (between 7.6 and $8.5 \mathrm{~km} \mathrm{~s}^{-1}$ ) compared to other 205 rays sampling areas unaffected by fracture zones. Velocity estimates in the vicinity of the St. 206 Paul fracture zone itself (from transform faulting events detected by hydrophones H2, H4 and 
207 H5, and ASPSP) show considerable variation, ranging from 8.0 to $9.1 \mathrm{~km} \mathrm{~s}^{-1}$ and a mean of 8.4

$208 \mathrm{~km} \mathrm{~s}^{-1}$, and little apparent spatial consistency. Among these events, we encountered one of the

209 highest $P n$ velocities $\left(9.0 \mathrm{~km} \pm 0.2 \mathrm{~s}^{-1}\right)$ in this study, for a ray path oriented roughly parallel to

210 the St. Paul transform fault (ray azimuth $\sim 105^{\circ}$ ) between an event near the St. Paul islets and 211 detected by hydrophone $\mathrm{H} 4$.

212 South of the St. Paul fracture zone, ray paths from events detected by hydrophone EA8

213 showed considerable variation in upper-mantle velocity, which range from 7.2 to $9.0 \mathrm{~km} \mathrm{~s}^{-1}$. Ray

214 paths originating from the spreading axis north of the St. Paul transform fault and trending $\sim 170^{\circ}$

215 towards EA8, have velocities of 7.3-8.1 $\mathrm{km} \mathrm{s}^{-1}$, while ray paths from the St. Paul transform fault

216 trending $\sim 185^{\circ}$ towards EA8 have consistently higher velocities of $7.6-9.1 \mathrm{~km} \mathrm{~s}^{-1}$.

217 Only 12 ray paths sampling the upper-mantle parallel and adjacent to the spreading axis

218 between the southern extent of the St. Paul transform fault and the Romanche transform fault are

219 available. This relatively poor coverage in ray paths in this area hinders our interpretation, where

220 velocities range from 7.2 to $8.3 \mathrm{~km} \mathrm{~s}^{-1}$.

221

222 Discussion

223 Upper-mantle velocity structure

224 In general, rays originating from the St. Paul transform system have higher velocities than 225 those originating from active spreading centers to the east and west (Figure 5a), probably due to 226 cooler conditions at the Moho along the transform. Our estimates of upper-mantle $P n$ velocities

227 broadly agree (within error) with $P n$ velocities from radially stratified velocity models such as 228 PREM (Dziewonski and Anderson, 1981) and iasp91 (Figure 6; Kennett and Engdahl, 1991).

229 Our $P n$ velocity estimates are also consistent with mantle velocity estimates from a series of 
230 reversed wide-angle refraction seismic profiles (i.e. with multiple shot points giving overlapping 231 coverage) collected in the equatorial Atlantic during R/V Atlantis cruise A180 (Figure 5b; Le

232 Pichon et al., 1965). The modal difference in velocity between refraction profiles from Le

233 Pichon et al. (1965) and all intersecting ray paths is $0.2 \mathrm{~km} \mathrm{~s}^{-1}$ (see histogram in Figure 5c),

234 although our $P n$ velocity estimates are consistently lower than those reported by Le Pichon et al.

235 (1965), with a maximum disagreement of $1.2 \mathrm{~km} \mathrm{~s}^{-1}$. A mantle velocity of $8.30 \mathrm{~km} \mathrm{~s}^{-1}$ was

236 reported along profile A180-48, which is $283 \mathrm{~km}-\mathrm{long}$, and crosses the eastern side of the St.

237 Paul transform fault (near $\sim 26.3^{\circ} \mathrm{W}$ ), trending northeast-southwest (Figure $5 \mathrm{~b}$ ). This velocity is

238 consistent with that inferred from $P n$ ray paths with a similar orientation, originating from

239 earthquakes on the St. Paul transform fault that were detected by hydrophone EA8. Ray paths

240 that intersect profile A180-48 (at angles either perpendicular or oblique to the trend of the

241 refraction profile) typically indicate lower upper-mantle velocities, ranging from 7.3 to $8.1 \mathrm{~km} \mathrm{~s}^{-}$

242 ', with the exception of one anomalous ray path oriented parallel with the St. Paul transform fault

243 with a velocity of $9.0 \mathrm{~km} \mathrm{~s}^{-1}$. Refraction profiles A180-40 and -42 are oriented roughly east-

244 west, are located $\sim 100 \mathrm{~km}$ north of the Romanche transform fault, and have velocities of 8.03

245 and $8.49 \mathrm{~km} \mathrm{~s}^{-1}$, respectively. Although there are only four $P n$ ray paths near to these profiles,

246 with near-perpendicular orientation, they indicate velocities ranging from 7.6 to $8.2 \mathrm{~km} \mathrm{~s}^{-1}$, and

247 hence are in broad agreement with the refraction estimates. Our velocity estimates of 7.6 to 8.2

$248 \mathrm{~km} \mathrm{~s}^{-1}$ are also in agreement with a velocity estimate of $8.0 \mathrm{~km} \mathrm{~s}^{-1}$ from an active source

249 experiment near $18^{\circ} \mathrm{W}$ roughly perpendicular to the St. Paul fracture zone, which at this

250 longitude separates $40 \mathrm{Myr}$ old crust in the south from $70 \mathrm{Myr}$ old crust in the north (Growe et

$251 a l ., 2019)$. The general agreement between upper-mantle velocities from the refraction profiles 
252 and our $P n$ arrivals validates our results, and implies that spatial trends observed in the study 253 area are likely to be real.

254 Elsewhere along the MAR, between $10^{\circ}$ to $40^{\circ} \mathrm{N}$, a mean upper-mantle velocity of $8.0 \mathrm{~km}$ $255 \pm 0.1 \mathrm{~km} \mathrm{~s}^{-1}$ was estimated using a similar method to this study with $P n$ arrivals detected by an 256 array of autonomous hydrophones (Dziak et al., 2004). Ray paths used by Dziak et al., (2004) 257 often crossed the ridge axis, spanned a series of fracture zones, and extended onto older crust, 258 which may explain the close agreement in results. This result suggests that off-axis and on-axis 259 upper mantle characteristics are similar in the northern and equatorial Atlantic Ocean.

260 Near the Oceanographer transform fault on the MAR $\left(\sim 35^{\circ} \mathrm{N}\right)$, a two-dimensional 261 tomographic inversion of wide-angle seismic refraction data suggests velocities of 7.4-7.8 $\mathrm{km} \mathrm{s}^{-1}$

262 (Canales et al., 2000; Hooft et al., 2000). These results agree within error with our estimates of $263 P n$ velocity from rays sampling on-axis upper-mantle to the north of the St. Paul transform fault 264 (Figure 5b), which are typically $7.2-8.0 \mathrm{~km} \mathrm{~s}^{-1}$.

265

\section{Upper-mantle velocity and plate age}

Seismic velocities in the upper-mantle near to the ridge axis, i.e. in young lithosphere, are expected to be lower than in off-axis areas, due to upwelling of hot material (e.g. Turcotte and Schubert, 2002). Following the removal of minor gridding artifacts associated with fracture zone traces, we used a global crustal age model (Müller et al., 2008) to assign a mean crustal age

271 along each ray path, for comparison with $P n$ velocity (Figure 7a).

272 Ray paths sampling lithosphere younger than 10 Myr show a wide range of velocities,

273 with a mean of $7.9 \mathrm{~km} \mathrm{~s}^{-1}$ and standard deviation of $0.5 \mathrm{~km} \mathrm{~s}^{-1}$. Twenty ray paths yield velocities 274 less than $7.5 \mathrm{~km} \mathrm{~s}^{-1} . P n$ velocities for ray paths sampling lithosphere older than $20 \mathrm{Myr}$ are 
275 slightly higher, with a mean of $8.1 \mathrm{~km} \mathrm{~s}^{-1}$ and standard deviation of $0.3 \mathrm{~km} \mathrm{~s}^{-1}$, while only two

276 ray paths give velocities lower than $7.5 \mathrm{~km} \mathrm{~s}^{-1}$ (Figure 7a). Most rays cover a wide range of

277 crustal ages, so this geometry, and our averaging approach, may smear the possible effects of

278 lithospheric aging. The lack of rays travelling exclusively via older lithosphere may also obscure

279 any progressive trend between upper-mantle velocity and crustal age. However, the tendency

280 toward the inclusion of lower velocities in younger crust (Figure 7a) reflects the expected

281 variation with respect to the zone of axial upwelling.

282

283

\section{Azimuthal Seismic Anisotropy}

Laboratory experiments have shown that the mantle can experience significant shear

285

286

287

288

289

290

291

292

293

294

295

296

297 strain during corner flow at the ridge axis, leaving an anisotropic fabric in the lithospheric mantle

as minerals (e.g. olivine) are aligned into a lattice preferred orientation (LPO; e.g. Zhang and Karato, 1995; Nicolas and Christensen, 2011). Anisotropy consistent with a LPO formed by twodimensional mantle flow has been measured at some locations in the oceanic upper mantle, in particular at the fast-spreading East Pacific Rise (e.g. Raitt et al., 1969; Lin et al., 2016), however the strength of anisotropy varies widely, and debate remains about its origins (e.g. Mark et al., 2019). Since isochrons in this region are fairly uniform (Figure 5), $\mathrm{V}_{P n}$ anisotropy could be expected parallel to paleo-relative plate motion, although this assumption has been shown to not apply everywhere (VanderBeek and Toomey, 2017).

We investigated the dependence of mantle velocity with azimuth, and use epicentral distance as a proxy for depth of mantle penetration to group rays (Figure 7b). No discernable pattern is evident in rays grouped by epicentral distance, including those expected to sample deepest in the mantle with epicentral distances $>700 \mathrm{~km}$ (blue lines in Figure 7c). Removing 
rays with $\mathrm{V}_{P n}$ error $>0.4 \mathrm{~km} \mathrm{~s}^{-1}$ also does not resolve any azimuthal dependence (Figure $7 \mathrm{~d}$ ), nor does separating rays by mean crustal age (Figures $7 \mathrm{e}$ and $7 \mathrm{f}$ ). azimuthal dependence may be too subtle to be resolved by our $\mathrm{V}_{P n}$ estimates, given the uncertainties in hypocenter location and crustal thickness discussed above. Second, the slow thickened lithosphere that is dominantly cooled by conduction, thus inhibiting corner flow (e.g. Sleep, 1975). As a result, deformation could be accommodated by faulting at depths of 5-10 km beneath the Moho, reducing the viscous strain in the mantle at these depths, and suppressing the anisotropy recorded in the mantle (e.g. Ribe, 1989). Observations of weaker or anomalous anisotropy elsewhere in the Atlantic Ocean are consistent with our findings (e.g. Gaherty et al., 2004; Dunn et al., 2005). Third, complex, three-dimensional upwelling patterns near the ridge axis could result in anisotropy on relatively short wavelengths (Lin and Phipps Morgan, 1992), which would be smeared along our relatively long ray paths, and hence not be resolved.

\section{Pn and surface wave velocity}

To explore the relationship between $\mathrm{V}_{P n}$ and the thermal structure of the asthenospheric model SL2013sv (Schaeffer and Lebedev, 2013). Our objective is to evaluate our observations

317 of uppermost mantle properties in the context of deeper mantle properties. We do not aim to

318 directly validate our $\mathrm{V}_{P n}$ estimates via this comparison. This model was chosen because it is

319 particularly sensitive to anomalies within the upper-mantle, and hence provides a window into 320 the upper mantle structure directly beneath our $P n$ ray paths (Schaeffer and Lebedev, 2013). We 
321 extracted values of vertically polarized tomographic shear velocity anomaly $(\% d V s)$ at $100 \mathrm{~km}$

322 intervals along each ray path, from slices through the SL2013sv model at depths of 25, 50, 75

323 and $150 \mathrm{~km}$. We then calculated the mean $\% d V s$ along each ray path, at each depth interval

324 (Figure 8). At 25 and $50 \mathrm{~km}$ depths, the effects of the ridge axis are evident, with higher

325 velocities associated with ray paths travelling off-axis (detected by EA2 and EA8), and hence not

326 sampling the relatively low-velocity axial region (Figures $8 \mathrm{a}$ and $8 \mathrm{~b}$ ). This effect is less

327 pronounced at $75 \mathrm{~km}$ depth (Figure $8 \mathrm{c}$ ), and is not apparent at $150 \mathrm{~km}$ depth, which presumably

328 reflects sub-plate velocities. The lack of correlation between SL2013sv and $P n$ velocities at 150

$329 \mathrm{~km}$ suggests that our $\mathrm{V}_{P n}$ estimates, sensitive to the velocity structure directly beneath the Moho,

330 do not record deeper, larger-scale sub-plate (i.e. asthenospheric) processes and anomalies. Hence

331 our observed $\mathrm{V}_{P n}$ variability may instead arise due to local variations in melt supply, lithospheric

332 thickness, or faulting.

333

334 Conclusions

335 We used a network of five autonomous hydrophones and a broadband seismograph to

336 detect $P n$ arrivals from regional earthquakes in the equatorial Atlantic Ocean over a period of

$337 \sim 12$ months between 2012 and 2013. Our estimates of upper-mantle velocity from the travel

338 times of $152 P n$ arrivals broadly agree (mostly within $0.2 \mathrm{~km} \mathrm{~s}^{-1}$ ) with those from nearby seismic

339 refraction experiments.

340 We find that the upper-mantle near the St. Paul transform system has consistently high

341 velocities $\left(>8 \mathrm{~km} \mathrm{~s}^{-1}\right)$, compared to relatively low velocities $\left(\sim 7.5 \mathrm{~km} \mathrm{~s}^{-1}\right)$ in the adjacent MAR

342 spreading segments northwest of the transform. This spatial pattern is consistent with the notion

343 that $P n$ ray paths sample lower velocity mantle near the ridge axis, and higher velocity material 
344 near transforms, which are generally cooler, despite the presence of intra-transform spreading

345 segments. We do not resolve any dependence between $\mathrm{V}_{P n}$ and azimuth, which could either be

346 due to observational uncertainty, or due to the combined effects of thickened lithosphere and

347 more complex mantle upwelling patterns under slow-spreading conditions. We also do not find

348 any correlation between $V_{P n}$ and vertically polarized shear speed from the global SL2013sv

349 model, indicating that our method is not sensitive to properties of the asthenosphere. The close

350 agreement between our results and those from seismic refraction experiments demonstrates that

351 the relatively simple method of using sparse arrays of autonomous hydrophones to detect $P n$

352 arrivals can be used to obtain accurate estimates of upper-mantle velocities. Hence, this method

353 provides a useful complement to deployments of other seafloor instruments such as ocean

354 bottom seismographs, in remote areas where direct observations are typically elusive.

355

356 Data and Resources

357 All Pn velocities obtained in this study using the hydrophones data of the COLMEIA/EA array

358 (Smith et al., 2012; Maia et al., 2014) and the seismic records of the and ASPSP station (de Melo and do Nascimento., 2018), are presented in tables of Supplemental Material. Analysis and figure

360 preparation were carried out using the Generic Mapping Tools version 5.4.5 (Wessel et al.,

361 2013), Seismic Analysis Code (Helffrich et al., 2013). Earthquake locations used in this work

362 were obtained from the International Seismological Center Bulletin database at

363 www.isc.ac.uk/iscbulletin/search/bulletin/ (last accessed November 2019). The Global Centroid

364 Moment Tensor Project database of Ekström et al (2012) was searched

365 using www.globalcmt.org/CMTsearch.html (last accessed November 2019). 


\section{Acknowledgements}

370 This research was supported by National Science Foundation grants EAR-1062238, EAR3711062165 and OCE-1839727, and by an InterRidge Student Fellowship for GWSdM. The

372 COLMEIA expedition was funded by the French Ministry of Research through its grant to the 373 French Oceanographic Fleet. COLMEIA hydrophone deployment was funded by LABEX MER 374 grant "Actions à la mer", and instruments were recovered with the help of the Brazilian Navy.

375 AFdN thanks the support of the Brazilian Navy and CNPq for grants 392484441/2012-4 and 376 303817/2014-3. This paper is NOAA/Pacific Marine Environmental Laboratory contribution 377 number 5116. We thank Associate Editor, T. Brocher, B. VanderBeek, and an anonymous 378 reviewer for their constructive input. Any opinion, findings, and conclusions or 379 recommendations expressed in this material are those of the authors and do not necessarily 380 reflect the views of the National Science Foundation. 


\section{References}

383 Abercrombie, R. E., and G. Ekstrom (2001). Earthquake slip on oceanic transform faults, Nature 410, 74-77.

385

386

387

388

389

390

391

392

393

394

395

396

397

398

399

400

401

402

403

404

Barlow, J. (2019). Global Ocean Sound Speed Profile Library (GOSSPL), an Rdata resource for studies of ocean sound propagation, NOAA Tech. Memo. NMFS SWFSC 612, no. March, 17, doi: 10.25923/7DJ1-J540.

Bondár, I., and D. Storchak (2011). Improved location procedures at the International Seismological Centre, Geophys. J. Int. 186, no. 3, 1220-1244, doi: 10.1111/j.1365246X.2011.05107.x.

Brandsdottir, B., and W. Menke (1997). Faroe-Iceland Ridge Experiment, 2, Crustal structure of the Krafla central volcano, J. Geophys. Res. 102, no. B4, 7867-7886.

Campos, T., F. H. R. Bezerra, N. K. Srivastava, M. M. Vieira, and C. Vita-Finzi (2010). Holocene tectonic uplift of the St Peter and St Paul Rocks (Equatorial Atlantic) consistent with emplacement by extrusion, Mar. Geol. 271, no. 1-2, 177-186, doi: 10.1016/j.margeo.2010.02.013

Canales, J. P., J. A. Collins, and R. S. Detrick (2000). Seismic structure across the rift valley of the Mid-Atlantic Ridge at $23^{\circ} 20^{\prime}$ (MARK area): Implications for crustal accretion processes at slow spreading ridges, J. Geophys. Res. 105, no. B12, 28411-28425, doi: 10.1029/2000JB900301.

Christeson, G. L., J. A. Goff, and R. S. Reece (2019). Synthesis of Oceanic Crustal Structure From Two-Dimensional Seismic Profiles, Rev. Geophys. 57, doi: 10.1029/2019RG000641.

Chulick, G. S., S. Detweiler, and W. D. Mooney (2013). Seismic structure of the crust and uppermost mantle of South America and surrounding oceanic basins, J. South Am. Earth 
Confidential manuscript submitted to Bulletin of the Seismological Society of America

405

406

407

408

409

410

411

412

413

414

415

416

417

418

419

420

421

422

423

424

425

426

427

Sci. 42, 260-276, doi: 10.1016/j.jsames.2012.06.002.

Chulick, G. S., and W. D. Mooney (2002). Seismic Structure of the Crust and Uppermost Mantle of North America and Adjacent Oceanic Basins: A Synthesis, Bull. Seismol. Soc. Am. 92, no. 6, 2478-2492, doi: 10.1016/j.jsames.2012.06.002.

D’Eu, J. F., J. Y. Royer, and J. Perrot (2012). Long-term autonomous hydrophones for large-scale hydroacoustic monitoring of the oceans, in Proceedings of Oceans, 2012-Yeosu, IEEE, 1-6, doi: 10.1109/OCEANS-Yeosu.2012.6263519.

de Melo, G., and A. F. do Nascimento (2018). Earthquake Magnitude Relationships for the Saint Peter and Saint Paul Archipelago, Equatorial Atlantic, Pure Appl. Geophys. 175, no. 3, 741756, doi: 10.1007/s00024-017-1732-6.

DeMets, C., R. G. Gordon, and D. F. Argus (2010). Geologically current plate motions, Geophys. J. Int. 181, 1-80, doi: 10.1111/j.1365-246X.2009.04491.x.

Dunn, R. A., V. Lekić, R. S. Detrick, and D. R. Toomey (2005). Three-dimensional seismic structure of the Mid-Atlantic Ridge $\left(35^{\circ} \mathrm{N}\right)$ : Evidence for focused melt supply and lower crustal dike injection, J. Geophys. Res. Solid Earth 110, no. 9, 1-17, doi: 10.1029/2004JB003473.

Dziak, R. P., D. R. Bohnenstiehl, H. Matsumoto, C. G. Fox, D. K. Smith, M. Tolstoy, T. K. Lau, J. H. Haxel, and M. J. Fowler (2004). P- and T-wave detection thresholds, Pn velocity estimate, and detection of lower mantle and core P-waves on ocean sound-channel hydrophones at the Mid-Atlantic Ridge, Bull. Seism. Soc. Am. 94, no. 2, 665-677, doi: $10.1785 / 0120030156$

Dziewonski, A. M., and D. L. Anderson (1981). Preliminary reference Earth model, Phys. Earth Planet. Inter. 25, 297-356. 
Confidential manuscript submitted to Bulletin of the Seismological Society of America

Ekström, G., M. Nettles, and A. M. Dziewoński (2012). The global CMT project 2004-2010: Centroid-moment tensors for 13,017 earthquakes, Phys. Earth Planet. Inter. 200-201, 1-9, doi: 10.1016/j.pepi.2012.04.002.

Fox, C. G., H. Matsumoto, and T.-K. A. Lau (2001). Monitoring Pacific Ocean seismicity from an autonomous hydrophone array, J. Geophys. Res. 106, no. 10, 41834206, doi: 10.1029/2000JB900404.

Francis, T. J. G., I. T. Porter, and R. C. Lilwall (1978). Microearthquakes near the eastern end of St Paul's fracture zone, Geophys. J. R. Astron. Soc. 53Reprint, 201-217.

Gaherty, J. B., D. Lizarralde, J. A. Collins, G. Hirth, and S. Kim (2004). Mantle deformation during slow seafloor spreading constrained by observations of seismic anisotropy in the western Atlantic, Earth Planet. Sci. Lett. 228, no. 3-4, 255-265, doi: 10.1016/j.eps1.2004.10.026.

Gasperini, L., G. Carrara Marco Ligi, P. Fabretti, D. Brunelli, A. Cipriani, S. Susini, and P. Tartarotti (1997). New data on the geology of the Romanche FZ., equatorial Atlantic: PRIMAR-96 cruise report, $\mathbf{3}$, no. 59, 1-2.

Growe, K., I. Grevemeyer, S. Singh, and C. Papenberg (2019). Seismic structure of the St . Paul Fracture Zone near $18^{\circ} \mathrm{W}$ in the Atlantic Ocean - evidence for a magmatic origin of crust, Geophys. Res. Abstr. 21, 4770.

Helffrich, G., J. Wookey, and I. Bastow (2013). The Seismic Analysis Code: A Primer and User's Guide, Cambridge, UK.

Hooft, E. E. E., R. S. Detrick, D. R. Toomey, J. A. Collins, and J. Lin (2000). Crustal thickness and structure along three contrasting spreading segments of the Mid-Atlantic Ridge, $33.5^{\circ}$ 35N, J. Geophys. Res. Solid Earth 105, no. B4, 8205-8226, doi: 10.1029/1999jb900442. 
Confidential manuscript submitted to Bulletin of the Seismological Society of America

451 Kennett, B. L. N., and E. R. Engdahl (1991). Traveltimes for global earthquake location and 452 phase identification, Geophys. J. Int. 105, no. 2, 429-465, doi: 10.1111/j.1365246X.1991.tb06724.x.

454

455

456

457

458

459

460

461

462

463

464

465

466

467

468

469

470

471

472

473

Le Pichon, X., R. E. Houtz, C. L. Drake, and J. E. Nafe (1965). Crustal structure of the midocean ridges: 1. Seismic refraction measurements, J. Geophys. Res. 70, no. 2, 319-339, doi: 10.1029/jz070i002p00319.

Lin, P. Y. P., J. B. Gaherty, G. Jin, J. A. Collins, D. Lizarralde, R. L. Evans, and G. Hirth (2016). High-resolution seismic constraints on flow dynamics in the oceanic asthenosphere, Nature 535, no. 7613, 538-541, doi: 10.1038/nature18012.

Lin, J., and J. Phipps Morgan (1992). The spreading rate dependence of three-dimensional midocean ridge gravity structure, Geophys. Res. Lett. 19, no. 1, 13-16.

Linehan, D. (1940). Earthquakes in the West Indian region, Eos Trans. AGU 21, no. 2, 229-232, doi: doi:10.1029/TR021i002p00229.

Lohman, R. B., and M. Simons (2005). Locations of selected small earthquakes in the Zagros mountains, Geochemistry, Geophys. Geosystems 6, no. 3, doi: 10.1029/2004GC000849.

Maia, M., I. Brehme, U. F. Fluminense, A. Briais, and D. Brunelli (2014). Preliminary report on the COLMEIA Cruise, Equatorial Atlantic Recife, January 24 - Recife, February 28, 2013, InterRidge News 22, 52-56, doi: 10.1029/2005JB004210.Von.

Maia, M., S. Sichel, A. Briais, D. Brunelli, M. Ligi, N. Ferreira, T. Campos, B. Mougel, I. Brehme, C. Hémond, et al. (2016). Extreme mantle uplift and exhumation along a transpressive transform fault, Nat. Geosci. 9, no. 8, 619-623, doi: 10.1038/ngeo2759.

Mark, H. F., D. Lizarralde, J. A. Collins, N. C. Miller, G. Hirth, J. B. Gaherty, and R. L. Evans (2019). Azimuthal Seismic Anisotropy of 70-Ma Pacific-Plate Upper Mantle, J. Geophys. 
Confidential manuscript submitted to Bulletin of the Seismological Society of America

474

475

476

477

478

479

480

481

482

483

484

485

486

487

488

489

490

491

492

493

494

495

496

Res. Solid Earth 124, no. 2, 1889-1909, doi: 10.1029/2018JB016451.

Müller, R. D., M. Sdrolias, C. Gaina, and W. R. Roest (2008). Age, spreading rates, and spreading asymmetry of the world's ocean crust, Geochem. Geophys. Geosyst 9, no. 4, 119, doi: 10.1029/2007GC001743.

Nicolas, A., and N. I. Christensen (2011). Formation of anisotropy in upper mantle peridotites A review, in Composition, structure and dynamics of the lithosphere-asthenosphere system, Geodynamics K. Fuchs, and C. Froidevaux(Editors), American Geophysical Union, Washington, D. C., 111-123, doi: 10.1029/gd016p0111.

Raitt, R. W., J. Shor, G. G., T. J. G. Francis, and G. B. Morris (1969). Anisotropy of the Pacific upper mantle, J. Geophys. Res. 74, no. 12, 3095-3109, doi: https://doi.org/10.1029/JB074i012p03095.

Ribe, N. M. (1989). Seismic anisotropy and mantle flow, J. Geophys. Res. 94, no. B4, 42134223, doi: 10.1029/JB094iB04p04213.

Schaeffer, A. J., and S. Lebedev (2013). Global shear speed structure of the upper mantle and transition zone, Geophys. J. Int. 194, no. 1, 417-449, doi: 10.1093/gji/ggt095.

Sleep, N. H. (1975). Formation of Oceanic Crust: Some Thermal Constraints, J. Geophys. Res. 80, no. $29,4037-4042$.

Smith, D. K., R. P. Dziak, C. Palmiotto, R. Parnell-Turner, and A. Zheleznov (2012). The seismicity of the equatorial Mid-Atlantic Ridge and its long-offset transforms, Abstr. OS13B-1720 Present. 2012 Fall Meet. AGU, San Fr. Calif. 5-9 Dec.

Taylor, J. (1997). Introduction to Error Analysis, the Study of Uncertainties in Physical Measurements, University Science Books, New York, NY.

Turcotte, D. L., and G. Schubert (2002). Geodynamics, Cambridge University Press, doi: 
Confidential manuscript submitted to Bulletin of the Seismological Society of America 10.1017/CBO9780511807442.

498 Udintsev, G. B., H. J., V. G. Udintsev, and A. B. Knjazev (1996). Topography of the Equatorial 499 Segment of the Mid-Atlantic Ridge After Multi-Beam Echo-sounding., in Equatorial $500 \quad$ Segment of the Mid-Atlantic Ridge: IOC Technical Series No. 46 G. B. Udintsev(Editor), 501 United Nations Educational, Scientific and Cultural Organization, Paris, France, 8-15. 502 VanderBeek, B. P., and D. R. Toomey (2017). Shallow Mantle Anisotropy Beneath the Juan de 503 Fuca Plate, Geophys. Res. Lett. 44, no. 22, 11,382-11,389, doi: 10.1002/2017GL074769.

504 Wessel, P., W. H. F. Smith, R. Scharoo, J. Luis, and F. Wobbe (2013). Generic Mapping Tools: 505 Improved Version Released, Eos Trans. $A G U$ 94, no. 45, 409-410.

506 Weston, J., A. M. G. Ferreira, and G. J. Funning (2012). Systematic comparisons of earthquake 507 source models determined using InSAR and seismic data, Tectonophysics 532-535, 61-81, 508 doi: $10.1016 /$ j.tecto.2012.02.001.

509 Zhang, Z., and S. Karato (1995). Lattice preferred orientation of olivine aggregates in simple $510 \quad$ shear, Nature 375, 774-777.

511 


\section{Author mailing addresses}

513

514 Departamento de Geofisica, Federal University of Rio Grande do Norte, Natal, Brazil

515 (GWSdM, AFN),gwsmelo@ufrn.edu.br

516 Institute of Geophysics and Planetary Physics, Scripps Institution of Oceanography, University

517 of California, San Diego, CA, USA

518 (RPT)

519 NOAA, Pacific Marine Environmental Laboratory, Newport, OR, USA

520 (RPD)

521

522 National Science Foundation, Alexandria, VA, USA

$523(\mathrm{DKS})$

524

525 Laboratoire Geosciences Ocean, CNRS and University of Brest

526 LGO-IUEM, rue Dumont Durville, 29280 Plouzane, France

527 (MM and JYR)

528

529

530 
531 Table 1. Details of seismograph (S) and hydrophone (H) sensors used for $P n$ analysis. Sensor

532 depth is given below sea level (bsl); water delay is based upon cable length, and water/crust

533 corrections are applied to each $P n$ ray path individually.

534

\begin{tabular}{lcccccccc}
\hline $\begin{array}{l}\text { Station } \\
\text { name }\end{array}$ & $\begin{array}{c}\text { Sensor } \\
\text { type }\end{array}$ & Lat, $^{\circ} \mathbf{N}$ & Lon, $^{\circ} \mathbf{E}$ & $\begin{array}{c}\text { Depth } \\
\text { bsl, } \mathbf{m}\end{array}$ & $\begin{array}{c}\text { Cable } \\
\text { length, } \mathbf{m}\end{array}$ & $\begin{array}{c}\text { Water } \\
\text { delay, } \\
\text { s }\end{array}$ & $\begin{array}{c}\text { Crust path } \\
\text { correction, } \\
\text { km }\end{array}$ & $\begin{array}{c}\text { Crust travel } \\
\text { time } \\
\text { correction, s }\end{array}$ \\
\hline ASPSP & S & 0.9169 & -29.3459 & -16 & - & - & 12.5 & 1.9 \\
EA2 & H & 4.9907 & -22.9931 & 800 & 3912 & 2.10 & 23.8 & 7.2 \\
EA8 & H & -2.5159 & -29.2181 & 800 & 3242 & 2.54 & 23.0 & 6.5 \\
H2 & H & 1.3297 & -31.3445 & 700 & 2260 & 1.57 & 21.8 & 5.5 \\
H4 & H & 0.4123 & -24.6437 & 700 & 1860 & 1.24 & 21.3 & 5 \\
H5 & H & 0.1552 & -27.7875 & 700 & 3060 & 2.04 & 22.8 & 6.3 \\
\hline
\end{tabular}

535

536

537

538

539

540

541

542

543

544

545

546

547 


\section{Figures}

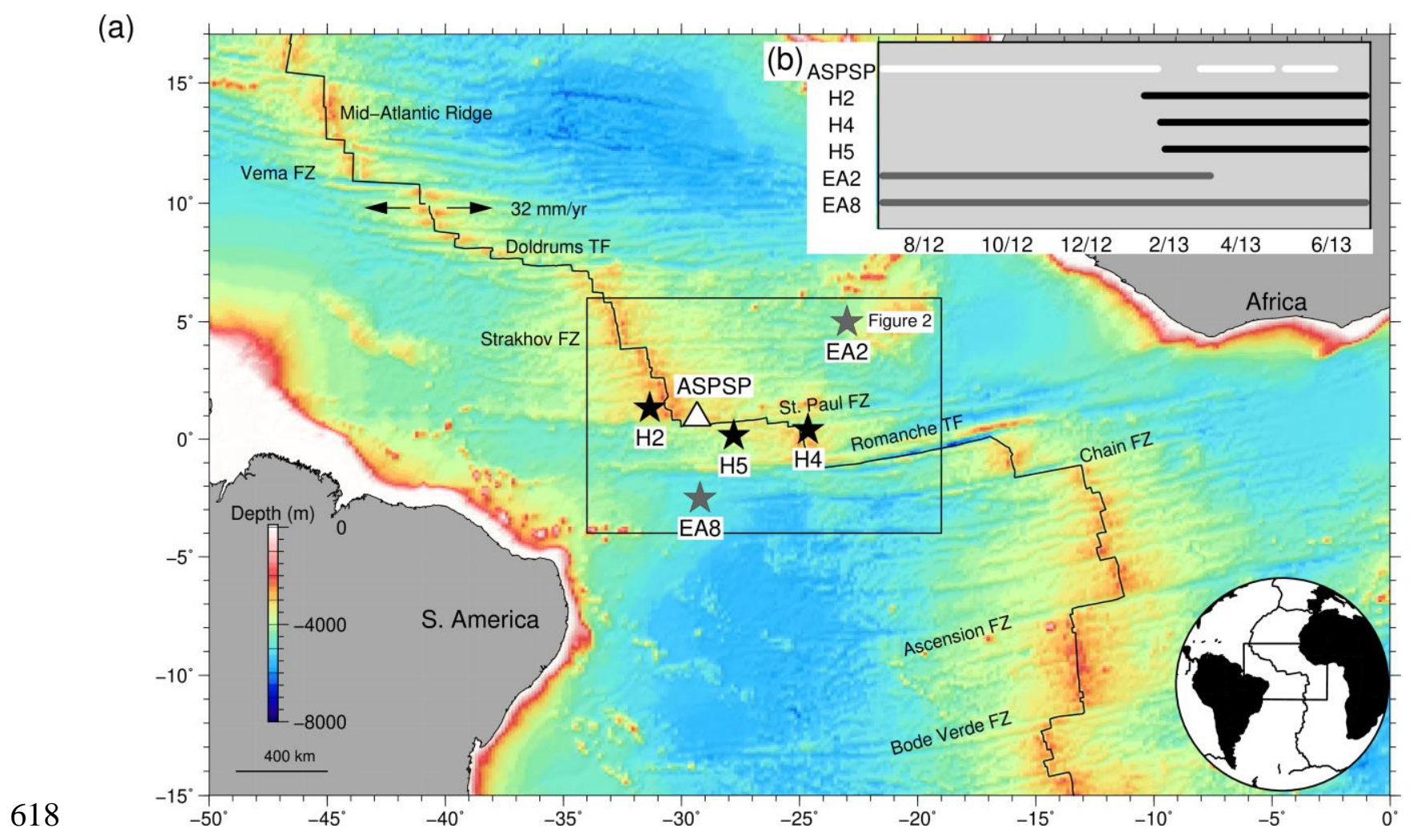

619

620 Figure 1. a) Regional bathymetric map of equatorial Atlantic ocean. White triangle shows

621 ASPSP seismograph station, located on St. Peter and St. Paul islets; black/gray stars are

622 COLMEIA / EA hydrophone networks, respectively (Smith et al., 2012; Maia et al., 2014); black

623 line is Mid-Atlantic Ridge, with selected transforms and half-spreading rate noted (arrows).

624 Black box shows location of Figure 2. b) Bars show instrument recording intervals: ASPSP

625 (white), COLMEIA (black), and EA (gray).

626

627

628 
(a)

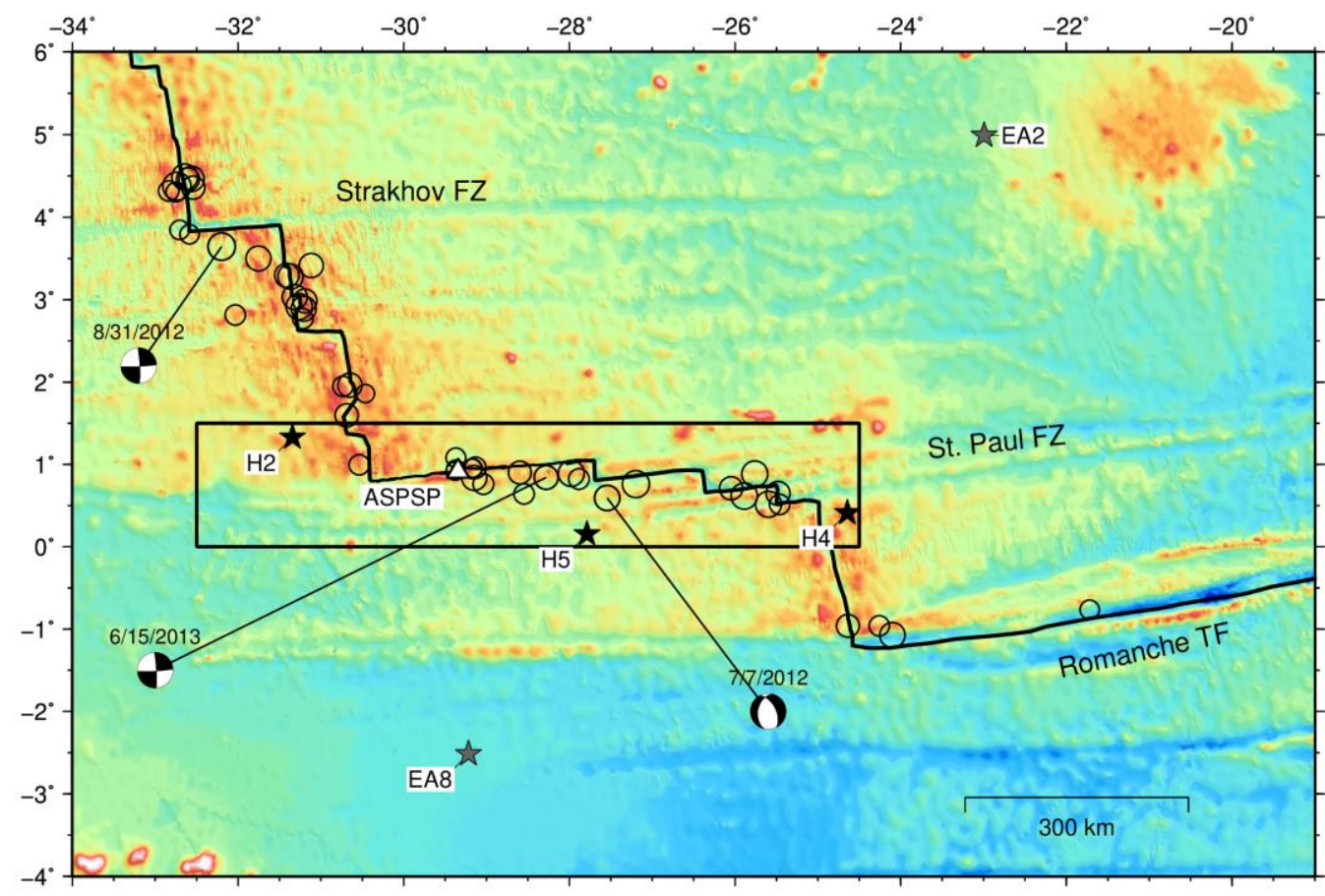

638

639

640

641

(b)

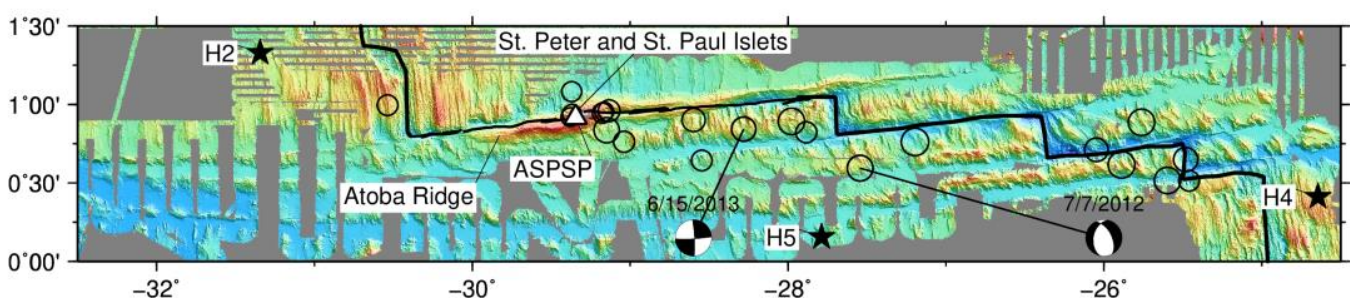

642
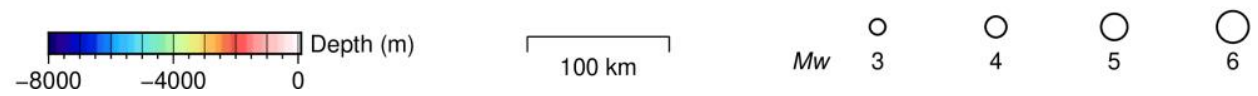

643

644

645 Figure 2. a) Bathymetric map of equatorial Atlantic ocean. Black box shows location of (b).

646 Circles are earthquakes used in $P n$ analysis, scaled by $\mathrm{M}_{\mathrm{W}}$; triangle shows ASPSP

647 station; black/gray stars are COLMEIA / EA hydrophone networks, respectively (Smith et al.,

648 2012; Maia et al., 2014); black line is Mid-Atlantic Ridge, with selected transforms labeled;

649 beach-balls are centroid moment tensors for three exemplar earthquakes (Ekström et al., 2012),

650 waveforms shown in Figures 4 and 5. b) Bathymetric map showing details of St. Peter and St.

651 Paul fracture zone (from Udintsev et al., 1996; Gasperini et al., 1997; Maia et al., 2016). 
(a)

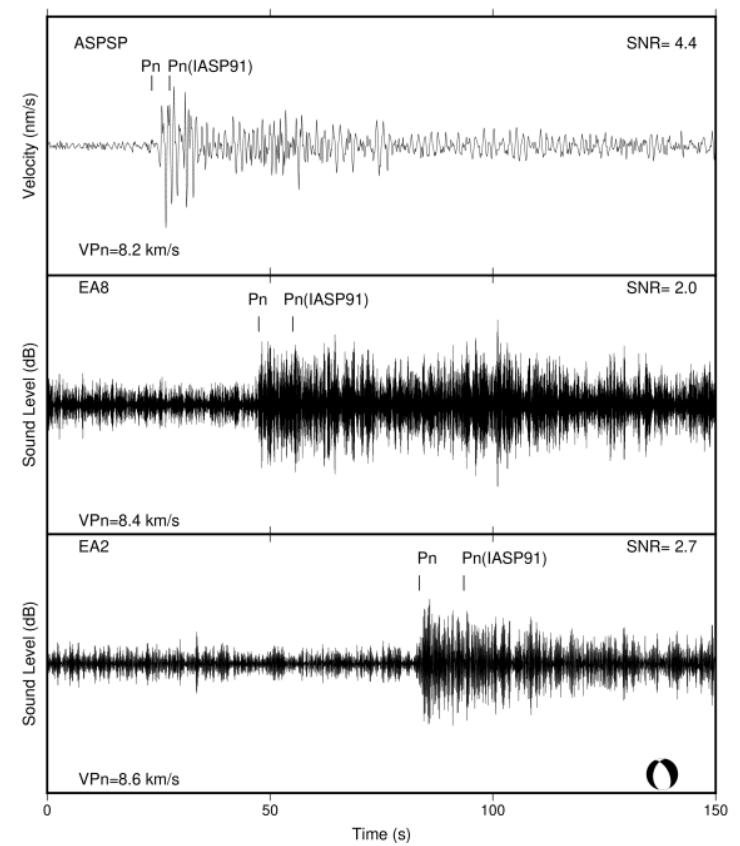

(b)

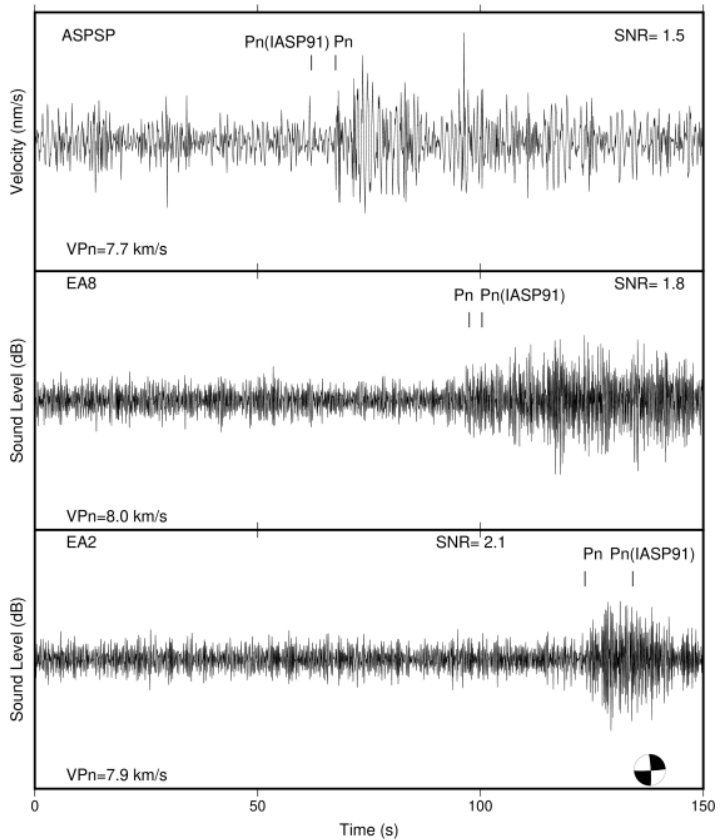

652

653 Figure 3. Example waveforms recorded by the ASPSP seismograph and EA array hydrophones, 654 with 4-12 Hz and 6-20 Hz Butterworth filters applied, respectively. a) $\mathrm{M}_{\mathrm{w}} 4.9$ normal faulting 655 event on $7^{\text {th }}$ July 2012 , located on the St. Paul transform fault at $27.5^{\circ} \mathrm{W}$. Picked $P n$ arrivals, and $656 P n$ arrivals predicted by iasp91 model are marked; beach-balls are centroid moment tensors 657 (Ekström et al., 2012); $\mathrm{V}_{P n}$ and signal to noise ratio (SNR) noted for each station (this study), 658 SNR calculated STA/LTA. b) Mw 5.3 strike-slip event on $31^{\text {st }}$ August 2012, located on Strakhov 659 transform fault near $32.5^{\circ} \mathrm{W}$. 


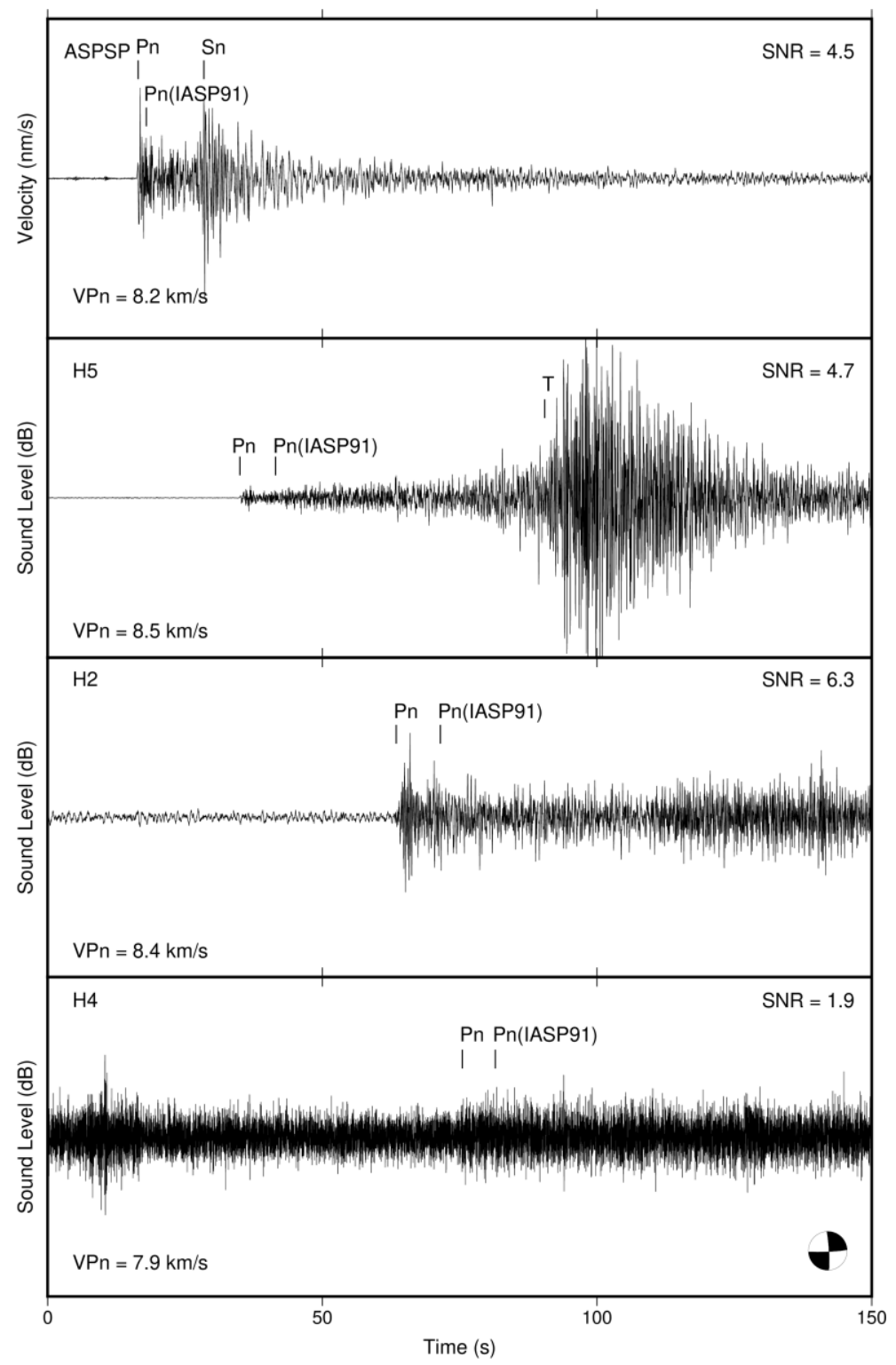

661

662 Figure 4. Example of waveforms recorded by the ASPSP seismograph and COLMEIA 663 hydrophones, with 4-12 Hz and 6-20 Hz Butterworth filters applied, respectively, for mb 4.6 664 strike-slip event on $15^{\text {th }}$ June 2013 , located near St. Paul transform fault at $29.5^{\circ}$ W. Picked Pn 665 arrivals, and $P n$ arrivals predicted by iasp91 model are marked; beach-balls are centroid moment 666 tensors (Ekström et al., 2012); $\mathrm{V}_{P n}$ and SNR noted for each station (this study). 

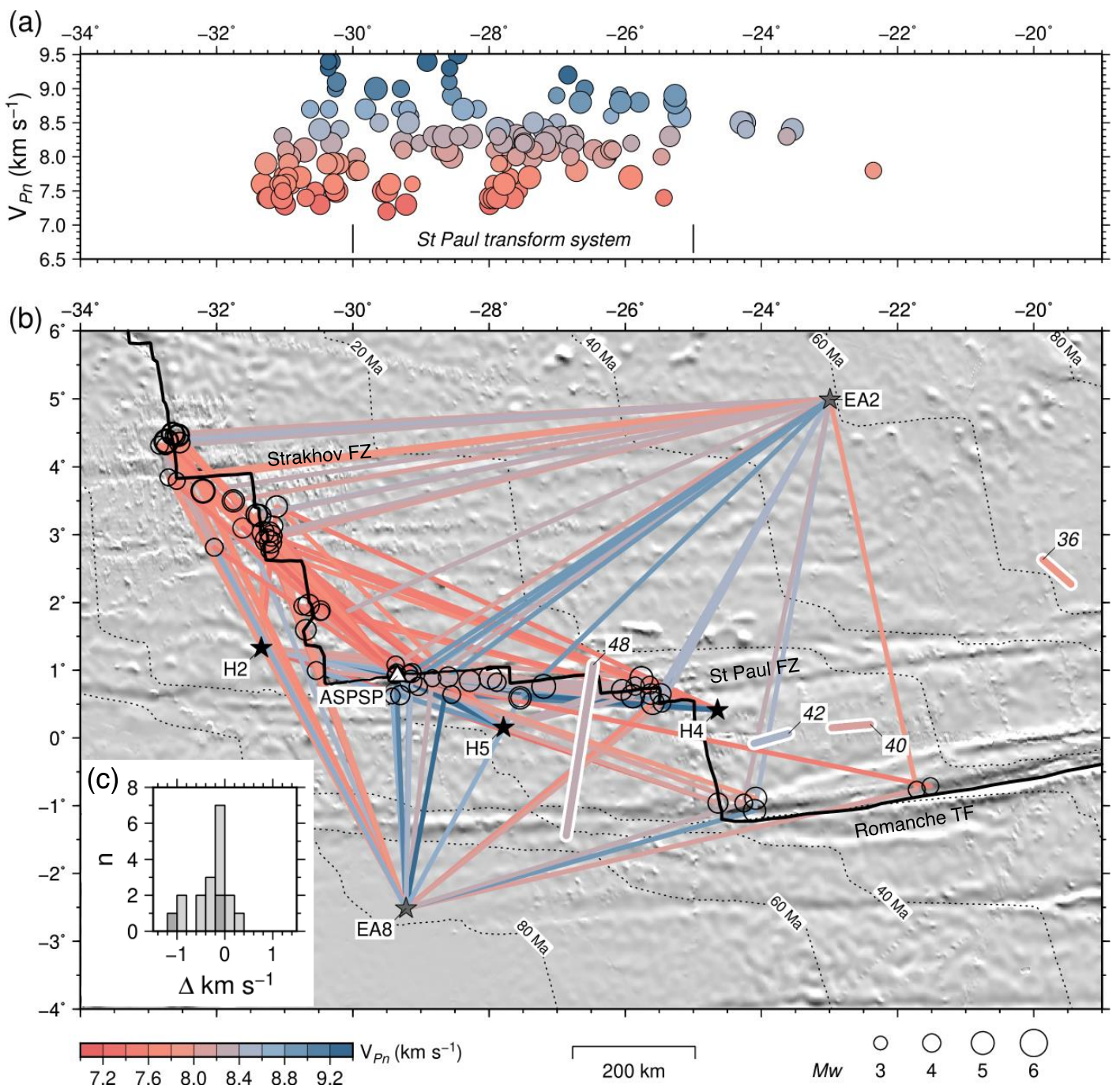

669

670 Figure 5. a) $V_{P n}$ plotted against mean longitude of ray path. Circle radius scaled by magnitude

671 of source event; colored by $\mathrm{V}_{P n}$; St. Paul transform system marked by vertical bars. b) Shaded

672 relief map showing stations, earthquakes, and ray paths. Circles are earthquakes used in $P n$

673 analysis, scaled by Mw; colored lines are ray paths shaded by $P n$ velocity; white triangle is

674 ASPSP station; black/gray stars are COLMEIA/EA hydrophone networks, respectively; thick

675 lines numbered 48, 42, 40, and 36 are seismic refraction profiles from cruise AT40-180 (Le

676 Pichon et al., 1965), shaded by velocity; dotted lines are isochrons, modified from Müller et al.

677 (2008) to remove artifacts associated with fracture zone traces. c) Histogram of difference 
678 between velocity estimates from refraction experiment (Le Pichon et al., 1965), and intersecting 679 ray paths from this study; positive values indicate higher velocities estimated by refraction 680 experiment; dark/light gray bars are velocities from profiles AT40-180 48 and 42, respectively. 681 


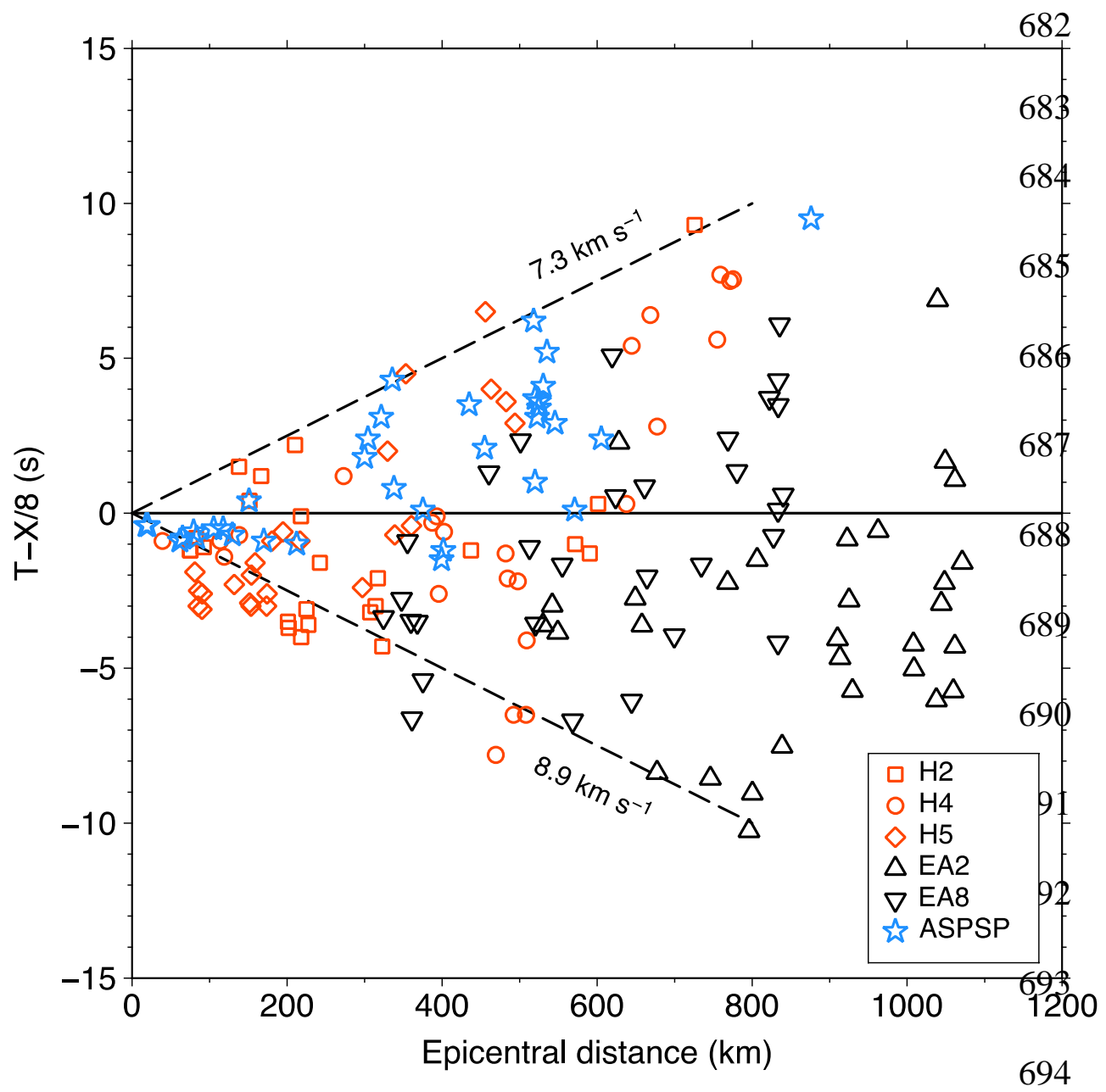

695

696 Figure 6. Reduced travel time versus epicentral distance, plotted with a reduction velocity of 8

$697 \mathrm{~km} \mathrm{~s}^{-1}$, approximately corresponding to velocity immediately below Moho from PREM and 698 iasp91 models (solid line; Dziewonski and Anderson, 1981; Kennett and Engdahl, 1991); dashed 699 lines show velocity bounds of 7.3 and $8.9 \mathrm{~km} \mathrm{~s}^{-1}$; key shows recording station symbols. 
(a)
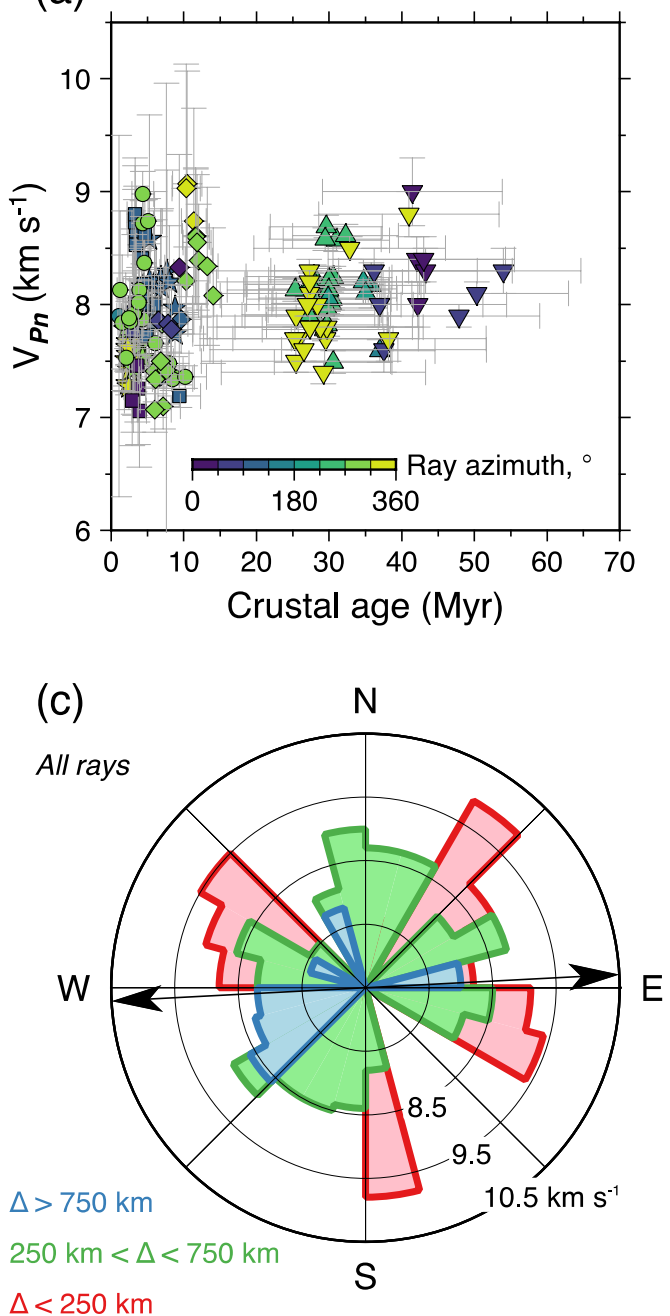

$\Delta<250 \mathrm{~km}$

(e)

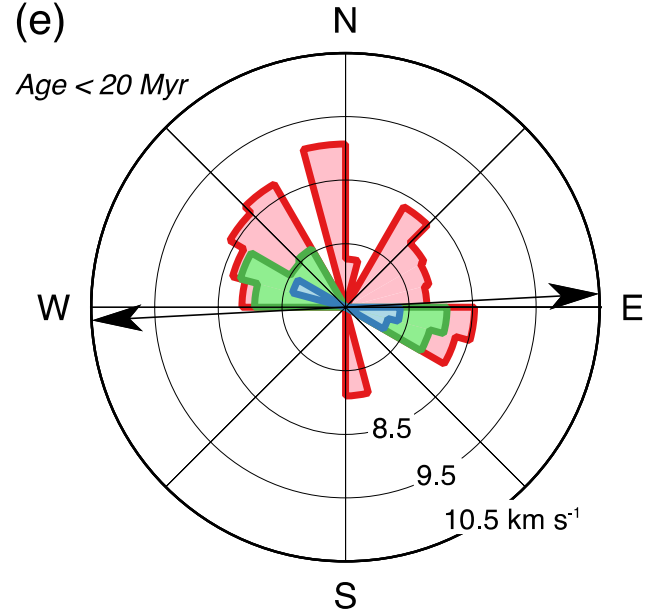

(b)

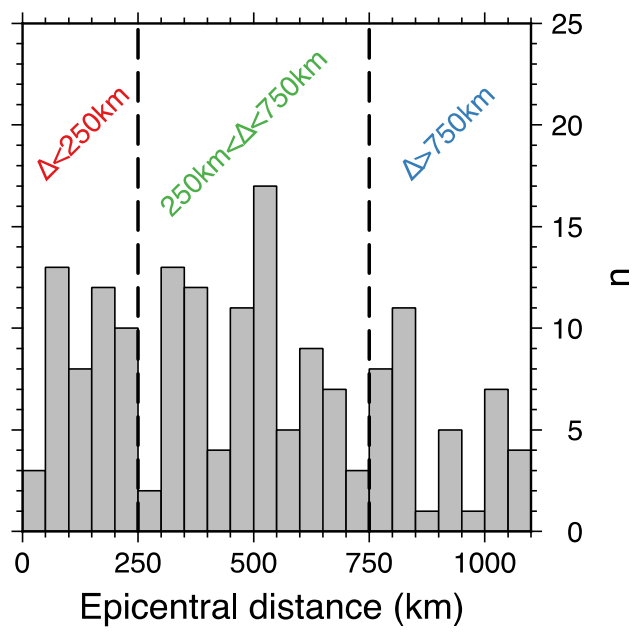

(d)

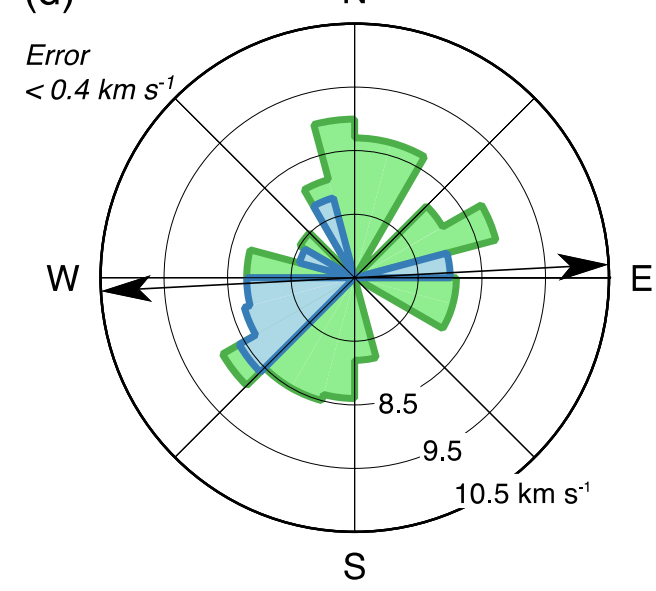

(f)

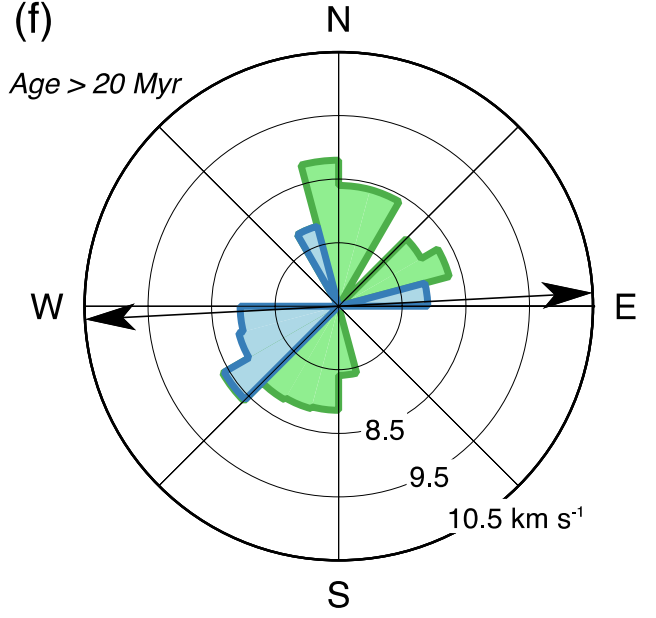


703 Figure 7. a) $\mathrm{V}_{P n}$ plotted against oceanic crustal age at epicentral location, colored by ray azimuth 704 (crustal ages assigned from model of Müller et al., 2008); key for station symbols given in 705 Figure 6; horizontal error bars are $2 \sigma$ crustal age along ray path, vertical error bars are $\mathrm{V}_{P n}$

706 uncertainty described in text. b) Histogram of epicentral distances; dotted lines show cut-offs 707 used to define categories in anisotropy analysis. e) Sector diagram showing $\mathrm{V}_{P n}$ vs. azimuth for

708 all rays; length of sectors scaled by median $\mathrm{V}_{P n}$, calculated in $15^{\circ}$ bins, and colored by epicentral 709 distance category; black arrows show plate spreading vector. d) Median $\mathrm{V}_{P n}$ vs. azimuth for rays 710 with $\mathrm{V}_{P n}$ uncertainty $<0.4 \mathrm{~km} \mathrm{~s}^{-1}$, colored by epicentral distance category. e) Median $\mathrm{V}_{P n} \mathrm{vs}$.

711 azimuth for rays sampling crust $<20 \mathrm{Myr}$ in age, colored by epicentral distance category. f)

712 Median $\mathrm{V}_{P n}$ vs. azimuth for rays sampling crust $>20 \mathrm{Myr}$ in age, colored by epicentral distance 713 category. 
(a)

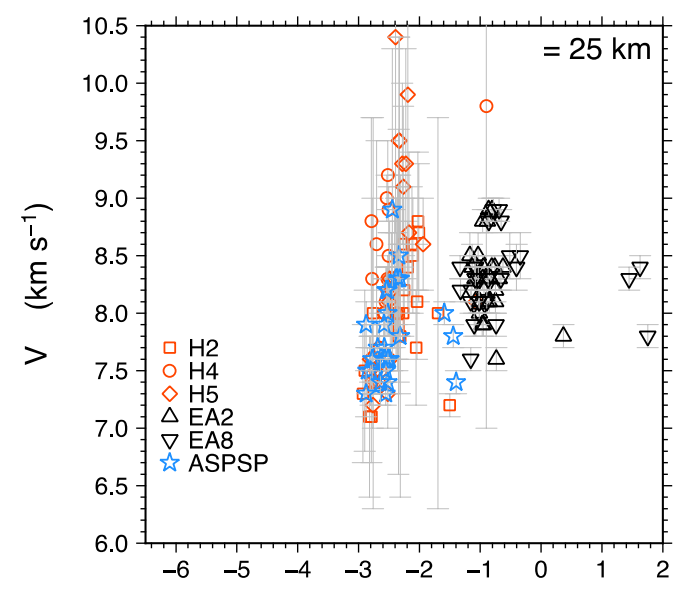

(c)

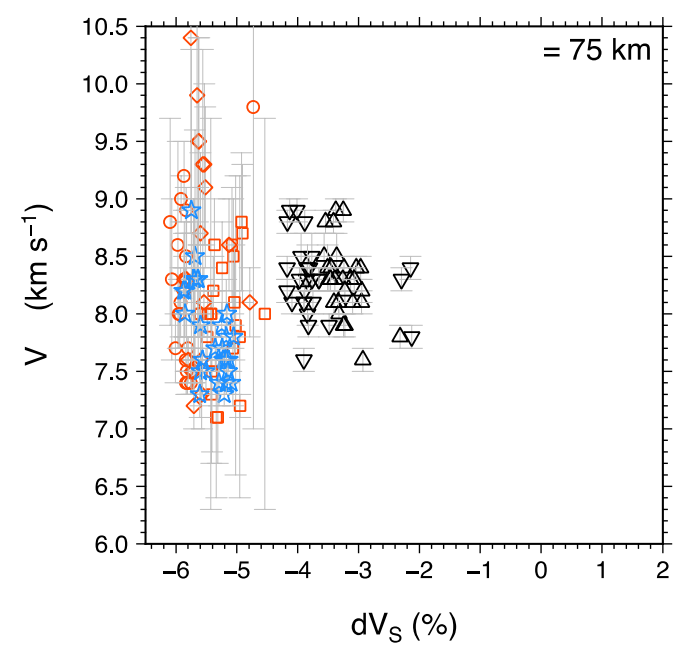

(b)

715

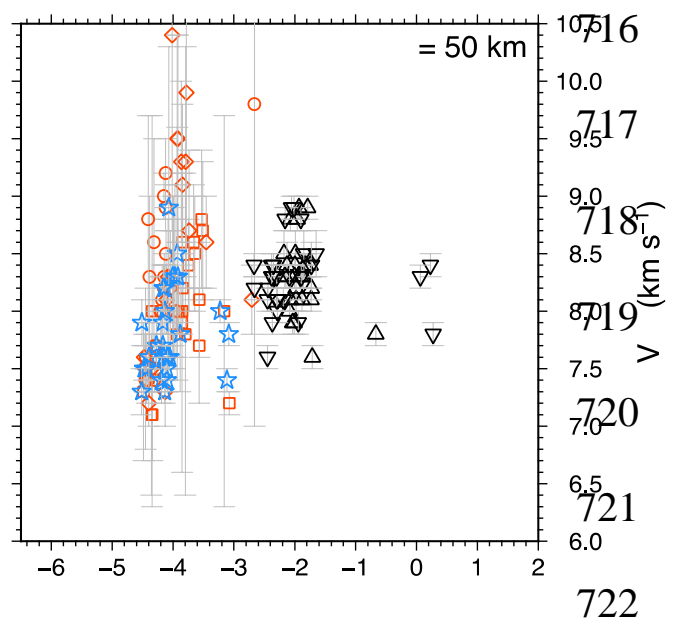

(d)

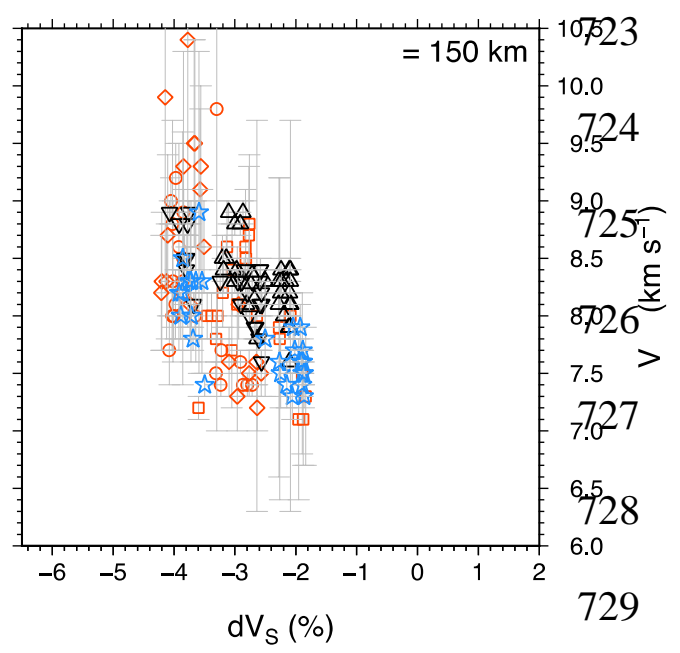

730

731 Figure 8. (a-d) Relationship between $V_{P n}$ and vertically polarized tomographic shear velocity 732 anomaly at depths of 25, 50,75 and $150 \mathrm{~km}$, respectively, from global model SL2013sv 733 (Schaeffer and Lebedev, 2013). 


\section{Supplemental Material for: Uppermost mantle velocity beneath the Mid- Atlantic Ridge and transform faults in the equatorial Atlantic ocean}

Guilherme W. S. de Melo, Ross Parnell-Turner, Robert P. Dziak, Deborah K. Smith, Marcia

Maia, Aderson F. do Nascimento, and Jean-Yves Royer

\section{Description of the Supplemental Material}

This supplemental material consists of one table, seven figures, accompanying narrative text and related references, and one Excel spreadsheet.

\section{Supplemental Text}

Table S1 provides the catalog of 50 earthquakes used in Pn velocity analysis, and the Table S2 contains the parameters used for $V_{P n}$ estimates from individual source-receiver pairs. Figures $\mathrm{S} 1$ to S6 show common-receiver record sections for each station used in the study, which aid the identification of $P n$ phases in the waveform data. As documented elsewhere, $P n$ arrivals are often emergent and noisy (e.g. VanderBeek and Toomey, 2017), and hence difficult to identify when plotted as record sections, in particular when using data recorded by moored hydrophones. We also note that microseism noise obscures $P n$ arrivals recorded by the station ASPSP at epicentral distances $>350 \mathrm{~km}$, due to this station being located on the St. Peter and St. Paul islets (de Queiroz et al., 2017). Figure S7 shows estimates of the signal to noise ratio (SNR), calculated for all arrivals, and used to illustrate uncertainties in arrival time picks. 


\section{Supplemental Tables}

Table S1. Catalog of 50 earthquakes used in Pn velocity analysis; magnitude estimates (de Melo and do Nascimento, 2018) hypocenters and origin times from ISC catalog. Note all depths are $10 \mathrm{~km}$.

Table S2. $V_{P n}$ parameters for velocity estimate for each source-receiver pair, including origin times, hypocenter locations, $P n$ travel time, $P n$ distance, and $P n$ velocity estimates for the 50 earthquakes. They present the complete list of 152 raypaths.

\section{Supplemental Figures}

Figures S1. Common-receiver record section for seismograph ASPSP on St Peter and St Paul islets; waveforms plotted with a 4-12 Hz Butterworth filter, amplitudes scaled to minimize overlap between adjacent traces; dashed solid/dashed lines show range of likely $P n$ velocities; colored triangles are $P n$ arrival picks.

Figures S2. Common-receiver record sections for hydrophone H2; waveforms plotted with a 6$20 \mathrm{~Hz}$ Butterworth filter, amplitudes scaled to minimize overlap between adjacent traces; dashed solid/dashed lines show range of likely $P n$ velocities; colored triangles are $P n$ arrival picks.

Figures S3. Common-receiver record sections for hydrophone H4; waveforms plotted with a 6$20 \mathrm{~Hz}$ Butterworth filter; amplitudes scaled to minimize overlap between adjacent traces; dashed solid/dashed lines show range of likely $P n$ velocities; colored triangles are $P n$ arrival picks. 
Figures S4. Common-receiver record section for hydrophone H5; waveforms plotted with a 6-20 $\mathrm{Hz}$ Butterworth filter, amplitudes scaled to minimize overlap between adjacent traces; dashed solid/dashed lines show range of likely $P n$ velocities; colored triangles are $P n$ arrival picks.

Figures S5. Common-receiver record section for hydrophone EA2; waveforms plotted with a 6$20 \mathrm{~Hz}$ Butterworth filter, amplitudes scaled to minimize overlap between adjacent traces; dashed solid/dashed lines show range of likely $P n$ velocities; colored triangles are $P n$ arrival picks.

Figures S6. Common-receiver record section for hydrophone EA8; waveforms plotted with a 6$20 \mathrm{~Hz}$ Butterworth filter, amplitudes scaled to minimize overlap between adjacent traces; dashed solid/dashed lines show range of likely $P n$ velocities; colored triangles are $P n$ arrival picks.

Figure S7. Noise characterization of $P n$ arrivals. a) Signal to noise ratio estimated from the ratio between short time ( $1 \mathrm{~s}$ window) and long time (20 s window) average amplitudes (SNRSTA/LTA), as a function of epicentral distance, key shows symbols used for stations. b) SNR estimated from ratio between the peak amplitude and the root mean square noise amplitude $\left(S N R_{a m p}\right)$, as a function of epicentral distance. c) $S N R_{S T A / L T A}$ as a function of magnitude. d) $S N R_{a m p}$ as a function of magnitude. e) $S N R_{S T A / L T A}$ vs. $S N R_{a m p}$, symbols with error bars are mean values of $S N R$ for each station \pm 1 standard deviation. 
Table S1. Catalog of 50 earthquakes used in $P n$ velocity analysis; magnitude estimates (de Melo and do Nascimento, 2018) hypocenters and origin times from ISC catalog. Note all depths are

$10 \mathrm{~km}$.

\begin{tabular}{|c|c|c|c|c|c|}
\hline Event & Date & Origin time, UTC & Lat, ${ }^{\circ} \mathrm{N}$ & Long, ${ }^{\circ} \mathrm{W}$ & Mag, Mw \\
\hline 1 & Jul. 07. 2012 & 15:11:45 & 0.594 & 27.544 & 4.9 \\
\hline 2 & Jul. 09. 2012 & $15: 40: 22$ & 0.836 & 29.149 & 4.8 \\
\hline 3 & Jul. 11. 2012 & $10: 48: 11$ & -0.961 & 24.259 & 3.9 \\
\hline 4 & Jul. 13. 2012 & $10: 00: 13$ & 2.814 & 32.034 & 3.9 \\
\hline 5 & Jul. 14. 2012 & $06: 47: 17$ & 3.281 & 31.366 & 4.9 \\
\hline 6 & Jul. 17. 2012 & $09: 21: 50$ & 2.917 & 31.263 & 5.0 \\
\hline 7 & Jul. 18. 2012 & 05:43:30 & 2.984 & 31.193 & 4.6 \\
\hline 8 & Jul. 28. 2012 & $15: 20: 17$ & 3.845 & 32.707 & 3.7 \\
\hline 9 & Jul. 28. 2012 & $15: 23: 42$ & 4.306 & 32.751 & 3.8 \\
\hline 10 & Jul. 28. 2012 & $16: 01: 11$ & 4.375 & 32.738 & 5.4 \\
\hline 11 & Jul. 28. 2012 & $16: 02: 33$ & 4.459 & 32.604 & 4.4 \\
\hline 12 & Jul. 28. 2012 & $16: 03: 59$ & 4.319 & 32.839 & 3.9 \\
\hline 13 & Jul. 28. 2012 & $16: 12: 38$ & 3.793 & 32.585 & 3.7 \\
\hline 14 & Jul. 28. 2012 & $16: 18: 46$ & 4.488 & 32.642 & 5.0 \\
\hline 15 & Aug. 09. 2012 & 08:59:23 & -1.072 & 24.099 & 4.9 \\
\hline 16 & Aug. 16. 2012 & 08:04:57 & 0.514 & 25.461 & 3.9 \\
\hline 17 & Aug. 18. 2012 & $16: 02: 47$ & 0.946 & 29.176 & 3.8 \\
\hline 18 & Aug. 22. 2012 & $10: 19: 55$ & 4.464 & 32.562 & 4.9 \\
\hline 19 & Aug. 23. 2012 & $05: 14: 32$ & 1.082 & 29.371 & 3.8 \\
\hline 20 & Aug. 31. 2012 & $00: 35: 35$ & 3.644 & 32.199 & 5.3 \\
\hline 21 & Aug. 31. 2012 & 03:52:29 & 3.5 & 31.753 & 4.8 \\
\hline 22 & Sep. 19. 2012 & $02: 26: 33$ & -0.764 & 21.719 & 3.7 \\
\hline 23 & Sep. 23. 2012 & 06:29:39 & 1.597 & 30.689 & 4.5 \\
\hline 24 & Sep. 24. 2012 & $00: 55: 51$ & 0.516 & 25.596 & 5.0 \\
\hline 25 & Oct. 26. 2012 & $14: 57: 30$ & 0.901 & 28.599 & 4.4 \\
\hline 26 & Oct. 31. 2012 & $15: 13: 12$ & 4.359 & 32.541 & 4.5 \\
\hline 27 & Nov. 11. 2012 & 08:02:28 & 3.296 & 31.411 & 4.7 \\
\hline 28 & Dec. 03. 2012 & $11: 03: 19$ & 0.649 & 25.481 & 4.6 \\
\hline 29 & Feb. 26. 2013 & $06: 29: 28$ & 0.762 & 29.039 & 4.0 \\
\hline 30 & Mar. 24. 2013 & $16: 23: 43$ & 0.616 & 25.888 & 5.1 \\
\hline 31 & Apr. 01. 2013 & $20: 01: 10$ & 0.892 & 27.978 & 5.0 \\
\hline 32 & Apr. 01.2013 & 20:03:00 & 0.823 & 27.885 & 4.0 \\
\hline 33 & Apr. 03. 2013 & 05:29:36 & 0.761 & 27.197 & 5.2 \\
\hline 34 & Apr. 08. 2013 & $20: 33: 41$ & 0.643 & 28.547 & 3.9 \\
\hline 35 & Apr. 09. 2013 & 03:07:04 & 3.415 & 31.118 & 4.7 \\
\hline 36 & Apr. 09. 2013 & $03: 46: 45$ & 2.892 & 31.208 & 4.8 \\
\hline 37 & Apr. 14. 2013 & $04: 28: 40$ & 2.769 & 31.218 & 3.9 \\
\hline 38 & Apr. 26. 2013 & $11: 06: 45$ & 0.711 & 26.047 & 4.5 \\
\hline 39 & May. 06. 2013 & $21: 15: 49$ & 0.94 & 29.37 & 3.6 \\
\hline 40 & May. 07. 2013 & 08:21:09 & 0.92 & 29.38 & 3.5 \\
\hline 41 & May. 21. 2013 & $00: 51: 04$ & -0.96 & 24.638 & 4.4 \\
\hline 42 & May. 28. 2013 & $22: 32: 39$ & 0.96 & 29.134 & 4.1 \\
\hline 43 & May. 31. 2013 & $10: 19: 26$ & 0.886 & 25.762 & 5.0 \\
\hline 44 & Jun. 12. 2013 & 03:54:05 & 0.955 & 29.165 & 3.6 \\
\hline 45 & Jun. 15. 2013 & $20: 37: 31$ & 0.843 & 28.281 & 4.6 \\
\hline 46 & Jul. 20. 2013 & 01:59:52 & 1.963 & 30.65 & 4.7 \\
\hline 47 & Jul. 20. 2013 & $12: 32: 49$ & 0.996 & 30.537 & 3.9 \\
\hline 48 & Jul. 21. 2013 & $14: 54: 12$ & 1.949 & 30.734 & 3.9 \\
\hline 49 & Jul. 25. 2013 & 05:13:50 & 1.86 & 30.462 & 3.5 \\
\hline 50 & Aug. 09. 2013 & $01: 26: 16$ & 3.032 & 31.316 & 4.8 \\
\hline
\end{tabular}

All depths of these earthquakes are $10 \mathrm{~km}$ in the ISC catalog. 
Table S2. $V_{P n}$ parameters for velocity estimate for each source-receiver pair, including origin times, hypocenter locations, $P n$ travel time, $P n$ distance, and $P n$ velocity estimates for the 50 earthquakes. They present the complete list of 152 raypaths.

\begin{tabular}{|c|c|c|c|c|c|c|c|c|c|c|c|c|}
\hline Station & Date (ISC) & $\begin{array}{c}\text { Origin } \\
\text { Time } \\
\text { (ISC) }\end{array}$ & $\begin{array}{c}\text { Lat } \\
\text { (ISC) }\end{array}$ & $\begin{array}{l}\text { Lon } \\
\text { (ISC) }\end{array}$ & $\begin{array}{l}\text { Dept } \\
\text { h. km } \\
\text { (ISC) }\end{array}$ & $\begin{array}{l}\text { Mag } \\
\text { (ISC) }\end{array}$ & $\begin{array}{l}\text { Great } \\
\text { Circle } \\
\text { Distan } \\
\text { ce. } k m\end{array}$ & $\begin{array}{c}\text { Pn } \\
\text { Distan } \\
\text { ce. km }\end{array}$ & $\begin{array}{c}\text { Travel } \\
\text { Time. } \\
\text { s }\end{array}$ & $\begin{array}{c}\text { Pn } \\
\text { Travel } \\
\text { Time. s }\end{array}$ & $\begin{array}{l}\text { Total } \\
\text { error. } \\
\mathrm{km} / \mathrm{s}\end{array}$ & $\begin{array}{l}\text { VPn. } \\
\text { km/s }\end{array}$ \\
\hline EA2 & 2012-07-07 & 15:11:45 & 0.59390 & -27.5438 & 10.0 & 4.9 & 701.2 & 677.4 & 83.5 & 76.3 & 0.1 & 8.9 \\
\hline EA8 & 2012-07-07 & $15: 11: 45$ & 0.59390 & -27.5438 & 10.0 & 4.9 & 391.1 & 368.1 & 49.0 & 42.5 & 0.3 & 8.7 \\
\hline ASPSP & 2012-07-07 & 15:11:45 & 0.59390 & -27.5440 & 10.0 & 4.0 & 183.6 & 170.0 & 22.4 & 20.4 & 0.5 & 8.3 \\
\hline EA2 & 2012-07-09 & $15: 40: 22$ & 0.83630 & -29.1490 & 10.0 & 4.8 & 824.2 & 800.4 & 98.2 & 91.0 & 0.1 & 8.8 \\
\hline EA8 & 2012-07-09 & $15: 40: 22$ & 0.83630 & -29.1490 & 10.0 & 4.8 & 370.8 & 347.8 & 47.2 & 40.7 & 0.3 & 8.5 \\
\hline ASPSP & 2012-07-11 & 10:48:11 & -0.96100 & -24.2591 & 10.0 & 3.9 & 584.7 & 571.1 & 73.5 & 71.5 & 0.1 & 8.0 \\
\hline EA2 & 2012-07-11 & 10:48:11 & -0.96100 & -24.2591 & 10.0 & 3.9 & 673.0 & 649.2 & 85.6 & 78.4 & 0.1 & 8.3 \\
\hline EA8 & 2012-07-11 & 10:48:11 & -0.96100 & -24.2591 & 10.0 & 3.9 & 577.9 & 554.9 & 74.2 & 67.7 & 0.2 & 8.2 \\
\hline EA2 & 2012-07-13 & 10:00:13 & 2.81410 & -32.0339 & 10.0 & 3.9 & 1032.0 & 1008.2 & 129.0 & 121.8 & 0.1 & 8.3 \\
\hline EA8 & 2012-07-13 & 10:00:13 & 2.81410 & -32.0339 & 10.0 & 3.9 & 667.5 & 644.5 & 81.0 & 74.5 & 0.1 & 8.7 \\
\hline ASPSP & 2012-07-13 & 10:00:13 & 2.81410 & -32.0339 & 10.0 & 3.9 & 335.1 & 321.5 & 45.3 & 43.3 & 0.2 & 7.4 \\
\hline EA2 & 2012-07-14 & 06:47:17 & 3.28140 & -31.3666 & 10.0 & 4.9 & 948.7 & 924.9 & 120.0 & 112.8 & 0.1 & 8.2 \\
\hline EA8 & 2012-07-14 & 06:47:17 & 3.28140 & -31.3666 & 10.0 & 4.9 & 684.2 & 661.2 & 90.0 & 83.5 & 0.1 & 7.9 \\
\hline ASPSP & 2012-07-14 & 06:47:17 & 3.28140 & -31.3666 & 10.0 & 4.4 & 349.2 & 335.6 & 48.2 & 46.2 & 0.2 & 7.3 \\
\hline EA2 & 2012-07-17 & 09:21:50 & 2.91710 & -31.2627 & 10.0 & 5.0 & 946.5 & 922.7 & 121.7 & 114.5 & 0.1 & 8.1 \\
\hline EA8 & 2012-07-17 & 09:21:50 & 2.91710 & -31.2627 & 10.0 & 5.0 & 642.4 & 619.4 & 89.0 & 82.5 & 0.1 & 7.5 \\
\hline ASPSP & 2012-07-17 & 09:21:50 & 2.91710 & -31.2627 & 10.0 & 4.5 & 313.6 & 300.0 & 41.3 & 39.3 & 0.3 & 7.6 \\
\hline EA2 & 2012-07-18 & 05:43:30 & 2.98460 & -31.1929 & 10.0 & 4.6 & 937.2 & 913.4 & 116.7 & 109.5 & 0.1 & 8.3 \\
\hline EA8 & 2012-07-18 & 05:43:30 & 2.98460 & -31.1929 & 10.0 & 4.6 & 646.7 & 623.7 & 85.0 & 78.5 & 0.1 & 7.9 \\
\hline ASPSP & 2012-07-18 & 05:43:30 & 2.98460 & -31.1929 & 10.0 & 4.3 & 318.0 & 304.4 & 42.5 & 40.5 & 0.3 & 7.5 \\
\hline EA2 & 2012-07-28 & 15:20:17 & 3.84550 & -32.7071 & 10.0 & 3.7 & 1085.6 & 1061.8 & 141.0 & 133.8 & 0.1 & 7.9 \\
\hline EA8 & 2012-07-28 & 15:20:17 & 3.84550 & -32.7071 & 10.0 & 3.7 & 803.4 & 780.4 & 105.4 & 98.9 & 0.1 & 7.9 \\
\hline
\end{tabular}




\begin{tabular}{|c|c|c|c|c|c|c|c|c|c|c|c|c|}
\hline ASPSP & 2012-07-28 & $15: 20: 17$ & 3.84550 & -32.7071 & 10.0 & 3.7 & 544.1 & 530.5 & 72.4 & 70.4 & 0.1 & 7.5 \\
\hline ASPSP & 2012-07-28 & $15: 23: 42$ & 4.30570 & -32.7514 & 10.0 & 3.8 & 538.6 & 525.0 & 71.2 & 69.2 & 0.1 & 7.6 \\
\hline EA2 & $2012-07-28$ & $15: 23: 42$ & 4.30570 & -32.7514 & 10.0 & 3.8 & 1085.4 & 1061.6 & 135.6 & 128.4 & 0.1 & 8.3 \\
\hline EA8 & 2012-07-28 & $15: 23: 42$ & 4.30570 & -32.7514 & 10.0 & 3.8 & 850.6 & 827.6 & 109.2 & 102.7 & 0.1 & 8.1 \\
\hline ASPSP & 2012-07-28 & 16:01:11 & 4.37560 & -32.7379 & 10.0 & 4.8 & 548.9 & 535.3 & 74.1 & 72.1 & 0.1 & 7.4 \\
\hline EA2 & $2012-07-28$ & 16:01:11 & 4.37560 & -32.7379 & 10.0 & 5.4 & 1083.3 & 1059.5 & 133.9 & 126.7 & 0.1 & 8.4 \\
\hline EA8 & $2012-07-28$ & 16:01:11 & 4.37560 & -32.7379 & 10.0 & 5.4 & 856.7 & 833.7 & 115.0 & 108.5 & 0.1 & 7.7 \\
\hline ASPSP & 2012-07-28 & $16: 02: 33$ & 4.45970 & -32.6045 & 10.0 & 4.4 & 533.7 & 520.1 & 70.7 & 68.7 & 0.1 & 7.6 \\
\hline EA2 & $2012-07-28$ & $16: 02: 33$ & 4.45970 & -32.6045 & 10.0 & 4.4 & 1067.9 & 1044.1 & 134.8 & 127.6 & 0.1 & 8.2 \\
\hline EA8 & 2012-07-28 & $16: 02: 33$ & 4.45970 & -32.6045 & 10.0 & 4.4 & 858.4 & 835.4 & 117.0 & 110.5 & 0.1 & 7.6 \\
\hline EA2 & $2012-07-28$ & $16: 03: 59$ & 4.31910 & -32.8387 & 10.0 & 3.9 & 1094.9 & 1071.1 & 139.5 & 132.3 & 0.1 & 8.1 \\
\hline EA8 & $2012-07-28$ & $16: 03: 59$ & 4.31910 & -32.8387 & 10.0 & 3.9 & 856.4 & 833.4 & 106.5 & 100.0 & 0.1 & 8.3 \\
\hline ASPSP & 2012-07-28 & $16: 03: 59$ & 4.31910 & -32.8387 & 10.0 & 3.9 & 538.6 & 525.0 & 71.0 & 69.0 & 0.1 & 7.6 \\
\hline EA2 & $2012-07-28$ & $16: 12: 38$ & 3.79280 & -32.5852 & 10.0 & 3.7 & 1072.9 & 1049.1 & 140.0 & 132.8 & 0.1 & 7.9 \\
\hline EA8 & $2012-07-28$ & $16: 12: 38$ & 3.79280 & -32.5852 & 10.0 & 3.7 & 791.8 & 768.8 & 105.0 & 98.5 & 0.1 & 7.8 \\
\hline ASPSP & 2012-07-28 & $16: 12: 38$ & 3.79280 & -32.5852 & 10.0 & 3.7 & 536.3 & 522.7 & 70.5 & 68.5 & 0.1 & 7.6 \\
\hline EA2 & 2012-07-28 & $16: 18: 46$ & 4.48820 & -32.6422 & 10.0 & 5.0 & 1071.9 & 1048.1 & 136.0 & 128.8 & 0.1 & 8.1 \\
\hline EA8 & 2012-07-28 & $16: 18: 46$ & 4.48820 & -32.6422 & 10.0 & 5.0 & 863.1 & 840.1 & 112.1 & 105.6 & 0.1 & 8.0 \\
\hline ASPSP & 2012-07-28 & $16: 18: 46$ & 4.48820 & -32.6422 & 10.0 & 4.6 & 531.8 & 518.2 & 73.0 & 71.0 & 0.1 & 7.3 \\
\hline ASPSP & 2012-08-09 & $08: 59: 23$ & -1.07230 & -24.0997 & 10.0 & 4.8 & 618.9 & 605.3 & 80.1 & 78.1 & 0.1 & 7.8 \\
\hline EA2 & 2012-08-09 & $08: 59: 23$ & -1.07230 & -24.0997 & 10.0 & 4.9 & 681.6 & 657.8 & 85.8 & 78.6 & 0.1 & 8.4 \\
\hline EA8 & 2012-08-09 & $08: 59: 23$ & -1.07230 & -24.0997 & 10.0 & 4.9 & 591.4 & 568.4 & 70.9 & 64.4 & 0.2 & 8.8 \\
\hline EA2 & 2012-08-16 & 08:04:57 & 0.51390 & -25.4608 & 10.0 & 3.9 & 566.0 & 542.2 & 72.0 & 64.8 & 0.2 & 8.4 \\
\hline EA8 & 2012-08-16 & 08:04:57 & 0.51390 & -25.4608 & 10.0 & 3.9 & 535.8 & 512.8 & 69.5 & 63.0 & 0.2 & 8.1 \\
\hline ASPSP & 2012-08-16 & 08:04:57 & 0.51390 & -25.4608 & 10.0 & 3.9 & 412.9 & 399.3 & 50.4 & 48.4 & 0.2 & 8.2 \\
\hline EA2 & 2012-08-18 & $16: 02: 47$ & 0.94600 & -29.1760 & 10.0 & 3.8 & 819.9 & 796.1 & 96.5 & 89.3 & 0.1 & 8.9 \\
\hline EA8 & 2012-08-18 & $16: 02: 47$ & 0.94600 & -29.1760 & 10.0 & 3.8 & 382.8 & 359.8 & 48.0 & 41.5 & 0.3 & 8.7 \\
\hline ASPSP & 2012-08-22 & $10: 19: 55$ & 4.46400 & -32.5619 & 10.0 & 4.4 & 559.3 & 545.7 & 73.1 & 71.1 & 0.1 & 7.7 \\
\hline EA2 & $2012-08-22$ & $10: 19: 55$ & 4.46400 & -32.5619 & 10.0 & 4.9 & 1063.2 & 1039.4 & 144.0 & 136.8 & 0.1 & 7.6 \\
\hline EA8 & $2012-08-22$ & $10: 19: 55$ & 4.46400 & -32.5619 & 10.0 & 4.9 & 856.8 & 833.8 & 114.2 & 107.7 & 0.1 & 7.7 \\
\hline EA2 & $2012-08-23$ & $05: 14: 32$ & 1.08200 & -29.3710 & 10.0 & 3.8 & 830.2 & 806.4 & 106.5 & 99.3 & 0.1 & 8.1 \\
\hline
\end{tabular}




\begin{tabular}{|c|c|c|c|c|c|c|c|c|c|c|c|c|}
\hline EA8 & $2012-08-23$ & $05: 14: 32$ & 1.08200 & -29.3710 & 10.0 & 3.8 & 398.2 & 375.2 & 48.0 & 41.5 & 0.3 & 9.0 \\
\hline EA2 & 2012-08-31 & $00: 35: 35$ & 3.64410 & -32.1987 & 10.0 & 5.3 & 1032.6 & 1008.8 & 128.3 & 121.1 & 0.1 & 8.3 \\
\hline EA8 & 2012-08-31 & $00: 35: 35$ & 3.64410 & -32.1987 & 10.0 & 5.3 & 757.6 & 734.6 & 96.7 & 90.2 & 0.1 & 8.1 \\
\hline ASPSP & 2012-08-31 & $00: 35: 35$ & 3.64410 & -32.1987 & 10.0 & 4.8 & 468.5 & 454.9 & 61.0 & 59.0 & 0.2 & 7.7 \\
\hline EA2 & 2012-08-31 & $03: 52: 29$ & 3.50060 & -31.7535 & 10.0 & 4.8 & 986.4 & 962.6 & 127.0 & 119.8 & 0.1 & 8.0 \\
\hline EA8 & 2012-08-31 & $03: 52: 29$ & 3.50060 & -31.7535 & 10.0 & 4.8 & 722.6 & 699.6 & 90.0 & 83.5 & 0.1 & 8.4 \\
\hline ASPSP & 2012-08-31 & 03:52:29 & 3.50060 & -31.7535 & 10.0 & 4.0 & 448.6 & 435.0 & 59.9 & 57.9 & 0.2 & 7.5 \\
\hline EA2 & 2012-09-19 & $02: 26: 33$ & -0.76440 & -21.7191 & 10.0 & 3.7 & 652.0 & 628.2 & 88.0 & 80.8 & 0.1 & 7.8 \\
\hline EA8 & 2012-09-19 & $02: 26: 33$ & -0.76440 & -21.7191 & 10.0 & 3.7 & 856.6 & 833.6 & 110.8 & 104.3 & 0.1 & 8.0 \\
\hline ASPSP & 2012-09-19 & $02: 26: 33$ & -0.71000 & -21.5190 & 10.0 & 3.7 & 889.6 & 876.0 & 121.0 & 119.0 & 0.1 & 7.4 \\
\hline EA2 & 2012-09-23 & $06: 22: 39$ & 1.59680 & -30.6888 & 10.0 & 4.5 & 933.9 & 910.1 & 116.9 & 109.7 & 0.1 & 8.3 \\
\hline EA8 & $2012-09-23$ & $06: 22: 39$ & 1.59680 & -30.6888 & 10.0 & 4.5 & 483.3 & 460.3 & 65.4 & 58.9 & 0.2 & 7.8 \\
\hline ASPSP & 2012-09-23 & $06: 22: 39$ & 1.59680 & -30.6888 & 10.0 & 4.3 & 164.6 & 151.0 & 21.3 & 19.3 & 0.5 & 7.8 \\
\hline ASPSP & 2012-09-24 & $00: 55: 51$ & 0.51650 & -25.5963 & 10.0 & 4.0 & 388.8 & 375.2 & 49.0 & 47.0 & 0.2 & 8.0 \\
\hline EA2 & 2012-09-24 & $00: 55: 51$ & 0.51650 & -25.5963 & 10.0 & 5.0 & 573.2 & 549.4 & 72.0 & 64.8 & 0.2 & 8.5 \\
\hline EA8 & 2012-09-24 & $00: 55: 51$ & 0.51650 & -25.5963 & 10.0 & 5.0 & 524.3 & 501.3 & 71.5 & 65.0 & 0.2 & 7.7 \\
\hline EA2 & $2012-10-26$ & $14: 57: 30$ & 0.90120 & -28.5988 & 10.0 & 4.4 & 769.9 & 746.1 & 91.9 & 84.7 & 0.1 & 8.8 \\
\hline EA8 & 2012-10-26 & $14: 57: 30$ & 0.90120 & -28.5988 & 10.0 & 4.4 & 384.0 & 361.0 & 45.0 & 38.5 & 0.3 & 9.4 \\
\hline ASPSP & 2012-10-26 & $14: 57: 30$ & 0.90120 & -28.5988 & 10.0 & 4.4 & 78.7 & 65.1 & 9.3 & 7.3 & 1.4 & 8.9 \\
\hline ASPSP & 2012-10-31 & $15: 13: 12$ & 4.35950 & -32.5410 & 10.0 & 4.4 & 533.4 & 519.8 & 68.0 & 66.0 & 0.2 & 7.9 \\
\hline EA2 & 2012-10-31 & $15: 13: 12$ & 4.35950 & -32.5410 & 10.0 & 4.5 & 1061.6 & 1037.8 & 130.9 & 123.7 & 0.1 & 8.4 \\
\hline EA8 & 2012-10-31 & $15: 13: 12$ & 4.35950 & -32.5410 & 10.0 & 4.5 & 845.4 & 822.4 & 113.0 & 106.5 & 0.1 & 7.7 \\
\hline ASPSP & 2012-11-11 & 08:02:28 & 3.29600 & -31.4112 & 10.0 & 4.5 & 351.4 & 337.8 & 45.0 & 43.0 & 0.2 & 7.9 \\
\hline EA2 & 2012-11-11 & 08:02:28 & 3.29600 & -31.4112 & 10.0 & 4.7 & 953.2 & 929.4 & 117.7 & 110.5 & 0.1 & 8.4 \\
\hline EA8 & 2012-11-11 & 08:02:28 & 3.29600 & -31.4112 & 10.0 & 4.7 & 687.4 & 664.4 & 87.5 & 81.0 & 0.1 & 8.2 \\
\hline ASPSP & 2012-12-03 & 11:03:19 & 0.64900 & -25.6250 & 10.0 & 4.5 & 415.2 & 401.6 & 51.0 & 49.0 & 0.2 & 8.2 \\
\hline EA2 & $2012-12-03$ & 11:03:19 & 0.64940 & -25.4813 & 10.0 & 4.6 & 554.0 & 530.2 & 69.9 & 62.7 & 0.2 & 8.5 \\
\hline EA8 & 2012-12-03 & 11:03:19 & 0.64940 & -25.4813 & 10.0 & 4.6 & 543.6 & 520.6 & 68.0 & 61.5 & 0.2 & 8.5 \\
\hline $\mathrm{H} 2$ & $2013-02-26$ & $06: 29: 28$ & 0.76200 & -29.0390 & 10.0 & 4.0 & 264.2 & 242.4 & 34.2 & 28.7 & 0.5 & 8.4 \\
\hline $\mathrm{H} 4$ & $2013-02-26$ & $06: 29: 28$ & 0.76200 & -29.0390 & 10.0 & 4.0 & 490.8 & 469.5 & 55.9 & 50.9 & 0.3 & 9.2 \\
\hline H5 & 2013-02-26 & $06: 29: 28$ & 0.76200 & -29.0390 & 10.0 & 4.0 & 154.6 & 131.8 & 20.5 & 14.2 & 1.0 & 9.3 \\
\hline
\end{tabular}




\begin{tabular}{|c|c|c|c|c|c|c|c|c|c|c|c|c|}
\hline $\mathrm{H} 2$ & $2013-03-24$ & $16: 23: 43$ & 0.61600 & -25.8880 & 10.0 & 5.1 & 612.4 & 590.6 & 78.0 & 72.5 & 0.2 & 8.1 \\
\hline $\mathrm{H} 4$ & 2013-03-24 & $16: 23: 43$ & 0.61600 & -25.8880 & 10.0 & 5.1 & 140.3 & 119.0 & 18.5 & 13.5 & 0.9 & 8.8 \\
\hline H5 & 2013-03-24 & $16: 23: 43$ & 0.61600 & -25.8880 & 10.0 & 5.1 & 217.5 & 194.7 & 30.0 & 23.7 & 0.5 & 8.2 \\
\hline ASPSP & 2013-04-01 & 20:01:10 & 0.89200 & -27.9790 & 10.0 & 5.0 & 131.0 & 117.4 & 16.2 & 14.2 & 0.7 & 8.3 \\
\hline $\mathrm{H} 2$ & 2013-04-01 & 20:01:10 & 0.89170 & -27.9786 & 10.0 & 5.0 & 344.5 & 322.7 & 41.5 & 36.0 & 0.4 & 9.0 \\
\hline $\mathrm{H} 4$ & 2013-04-01 & 20:01:10 & 0.89170 & -27.9786 & 10.0 & 5.0 & 408.5 & 387.2 & 53.1 & 48.1 & 0.3 & 8.0 \\
\hline H5 & 2013-04-01 & 20:01:10 & 0.89200 & -27.9790 & 10.0 & 5.0 & 108.0 & 85.2 & 14.0 & 7.7 & 1.9 & 11.1 \\
\hline ASPSP & 2013-04-01 & 20:03:00 & 0.82300 & -27.8850 & 10.0 & 4.0 & 143.0 & 129.4 & 17.5 & 15.5 & 0.7 & 8.3 \\
\hline $\mathrm{H} 2$ & 2013-04-01 & 20:03:00 & 0.82300 & -27.8850 & 10.0 & 4.0 & 338.8 & 317.0 & 43.0 & 37.5 & 0.3 & 8.5 \\
\hline $\mathrm{H} 4$ & 2013-04-01 & 20:03:00 & 0.82300 & -27.8850 & 10.0 & 4.0 & 414.3 & 393.0 & 54.0 & 49.0 & 0.3 & 8.0 \\
\hline $\mathrm{H} 5$ & 2013-04-01 & 20:03:00 & 0.82300 & -27.8850 & 10.0 & 4.0 & 113.0 & 90.2 & 14.5 & 8.2 & 1.8 & 11.0 \\
\hline ASPSP & 2013-04-03 & $05: 29: 36$ & 0.76100 & -27.1970 & 10.0 & 5.2 & 226.0 & 212.4 & 27.6 & 25.6 & 0.4 & 8.3 \\
\hline $\mathrm{H} 2$ & 2013-04-03 & $05: 29: 36$ & 0.76100 & -27.1970 & 10.0 & 5.2 & 459.2 & 437.4 & 59.0 & 53.5 & 0.2 & 8.2 \\
\hline $\mathrm{H} 4$ & 2013-04-03 & $05: 29: 36$ & 0.76100 & -27.1970 & 10.0 & 5.2 & 294.2 & 272.9 & 40.3 & 35.3 & 0.3 & 7.7 \\
\hline $\mathrm{H} 5$ & 2013-04-03 & $05: 29: 36$ & 0.91000 & -27.1970 & 10.0 & 5.2 & 103.8 & 81.0 & 14.5 & 8.2 & 1.7 & 9.9 \\
\hline ASPSP & 2013-04-08 & $20: 33: 41$ & 0.64300 & -28.5470 & 10.0 & 3.9 & 93.0 & 79.4 & 11.3 & 9.3 & 1.1 & 8.5 \\
\hline $\mathrm{H} 2$ & 2013-04-08 & $20: 33: 41$ & 0.64300 & -28.5470 & 10.0 & 3.9 & 239.6 & 217.8 & 32.6 & 27.1 & 0.5 & 8.0 \\
\hline $\mathrm{H} 4$ & 2013-04-08 & $20: 33: 41$ & 0.64300 & -28.5470 & 10.0 & 3.9 & 513.6 & 492.3 & 60.0 & 55.0 & 0.2 & 9.0 \\
\hline $\mathrm{H} 5$ & 2013-04-08 & $20: 33: 41$ & 0.64300 & -28.5470 & 10.0 & 3.9 & 181.5 & 158.7 & 24.5 & 18.2 & 0.7 & 8.7 \\
\hline $\mathrm{H} 2$ & 2013-04-09 & 03:07:04 & 3.41500 & -31.1180 & 10.0 & 4.7 & 231.9 & 210.1 & 34.0 & 28.5 & 0.4 & 7.4 \\
\hline $\mathrm{H} 4$ & 2013-04-09 & 03:07:04 & 3.41500 & -31.1180 & 10.0 & 4.7 & 793.0 & 771.7 & 109.0 & 104.0 & 0.1 & 7.4 \\
\hline H5 & 2013-04-09 & 03:07:04 & 3.41500 & -31.1180 & 10.0 & 4.7 & 516.9 & 494.1 & 71.0 & 64.7 & 0.2 & 7.6 \\
\hline $\mathrm{H} 2$ & 2013-04-09 & $03: 46: 45$ & 2.89200 & -31.2080 & 10.0 & 4.8 & 173.4 & 151.6 & 24.8 & 19.3 & 0.7 & 7.9 \\
\hline $\mathrm{H} 4$ & 2013-04-09 & $03: 46: 45$ & 2.89200 & -31.2080 & 10.0 & 4.8 & 780.1 & 758.8 & 107.5 & 102.5 & 0.1 & 7.4 \\
\hline $\mathrm{H} 5$ & 2013-04-09 & $03: 46: 45$ & 2.89200 & -31.2080 & 10.0 & 4.8 & 486.2 & 463.4 & 68.3 & 62.0 & 0.2 & 7.5 \\
\hline $\mathrm{H} 2$ & 2013-04-14 & 04:28:40 & 2.76900 & -31.2180 & 10.0 & 3.9 & 159.8 & 138.0 & 24.2 & 18.7 & 0.7 & 7.4 \\
\hline $\mathrm{H} 4$ & 2013-04-14 & 04:28:40 & 2.76900 & -31.2180 & 10.0 & 3.9 & 776.6 & 755.3 & 105.0 & 100.0 & 0.1 & 7.6 \\
\hline H5 & 2013-04-14 & 04:28:40 & 2.76900 & -31.2180 & 10.0 & 3.9 & 478.8 & 456.0 & 69.8 & 63.5 & 0.2 & 7.2 \\
\hline $\mathrm{H} 2$ & 2013-04-26 & $11: 06: 45$ & 0.71100 & -26.0470 & 10.0 & 4.5 & 593.6 & 571.8 & 76.0 & 70.5 & 0.2 & 8.1 \\
\hline $\mathrm{H} 4$ & $2013-04-26$ & 11:06:45 & 0.71100 & -26.0470 & 10.0 & 4.5 & 159.7 & 138.4 & 21.6 & 16.6 & 0.7 & 8.3 \\
\hline H5 & 2013-04-26 & 11:06:45 & 0.71100 & -26.0470 & 10.0 & 4.5 & 203.2 & 180.4 & 28.0 & 21.7 & 0.6 & 8.3 \\
\hline
\end{tabular}




\begin{tabular}{|c|c|c|c|c|c|c|c|c|c|c|c|c|}
\hline $\mathrm{H} 2$ & 2013-05-06 & $21: 15: 49$ & 0.94000 & -29.3700 & 10.0 & 3.6 & 223.7 & 201.9 & 27.0 & 21.5 & 0.6 & 9.4 \\
\hline $\mathrm{H} 4$ & 2013-05-06 & $21: 15: 49$ & 0.94000 & -29.3700 & 10.0 & 3.6 & 529.6 & 508.3 & 62.0 & 57.0 & 0.2 & 8.9 \\
\hline H5 & $2013-05-06$ & $21: 15: 49$ & 0.94000 & -29.3700 & 10.0 & 3.6 & 196.4 & 173.6 & 25.0 & 18.7 & 0.7 & 9.3 \\
\hline $\mathrm{H} 2$ & 2013-05-07 & 08:21:09 & 0.92000 & -29.3800 & 10.0 & 3.5 & 222.9 & 201.1 & 27.1 & 21.6 & 0.6 & 9.3 \\
\hline $\mathrm{H} 4$ & 2013-05-07 & 08:21:09 & 0.92000 & -29.3800 & 10.0 & 3.5 & 530.6 & 509.3 & 64.6 & 59.6 & 0.2 & 8.5 \\
\hline H5 & 2013-05-07 & 08:21:09 & 0.92000 & -29.3800 & 10.0 & 3.5 & 196.9 & 174.1 & 25.5 & 19.2 & 0.7 & 9.1 \\
\hline $\mathrm{H} 2$ & 2013-05-21 & 00:51:04 & -0.96000 & -24.6380 & 10.0 & 4.4 & 747.5 & 725.7 & 105.5 & 100.0 & 0.1 & 7.3 \\
\hline $\mathrm{H} 4$ & $2013-05-21$ & 00:51:04 & -0.96000 & -24.6380 & 10.0 & 4.4 & 60.5 & 39.2 & 9.0 & 4.0 & 2.8 & 9.8 \\
\hline $\mathrm{H} 5$ & 2013-05-21 & 00:51:04 & -0.96000 & -24.6380 & 10.0 & 4.4 & 361.7 & 338.9 & 48.0 & 41.7 & 0.3 & 8.1 \\
\hline $\mathrm{H} 2$ & 2013-05-28 & $22: 32: 39$ & 0.96000 & -29.1340 & 10.0 & 4.1 & 249.4 & 227.6 & 30.4 & 24.9 & 0.5 & 9.1 \\
\hline $\mathrm{H} 4$ & 2013-05-28 & $22: 32: 39$ & 0.96000 & -29.1340 & 10.0 & 4.1 & 503.5 & 482.2 & 64.0 & 59.0 & 0.2 & 8.2 \\
\hline H5 & $2013-05-28$ & $22: 32: 39$ & 0.96000 & -29.1340 & 10.0 & 4.1 & 174.3 & 151.5 & 22.3 & 16.0 & 0.9 & 9.5 \\
\hline $\mathrm{H} 2$ & 2013-05-31 & $10: 19: 26$ & 0.88600 & -25.7620 & 10.0 & 5.0 & 623.2 & 601.4 & 81.0 & 75.5 & 0.2 & 8.0 \\
\hline $\mathrm{H} 4$ & 2013-05-31 & 10:19:26 & 0.88600 & -25.7620 & 10.0 & 5.0 & 135.1 & 113.8 & 18.3 & 13.3 & 0.9 & 8.6 \\
\hline $\mathrm{H} 5$ & 2013-05-31 & 10:19:26 & 0.88600 & -25.7620 & 10.0 & 5.0 & 239.5 & 216.7 & 32.5 & 26.2 & 0.5 & 8.3 \\
\hline $\mathrm{H} 2$ & 2013-06-12 & 03:54:05 & 0.95500 & -29.1650 & 10.0 & 3.6 & 246.8 & 225.0 & 30.5 & 25.0 & 0.5 & 9.0 \\
\hline $\mathrm{H} 4$ & 2013-06-12 & 03:54:05 & 0.95500 & -29.1650 & 10.0 & 3.6 & 506.1 & 484.8 & 63.5 & 58.5 & 0.2 & 8.3 \\
\hline H5 & 2013-06-12 & 03:54:05 & 0.95500 & -29.1650 & 10.0 & 3.6 & 176.2 & 153.4 & 22.5 & 16.2 & 0.9 & 9.5 \\
\hline ASPSP & 2013-06-15 & $20: 37: 31$ & 0.84300 & -28.2810 & 10.0 & 4.6 & 118.8 & 105.2 & 14.7 & 12.7 & 0.8 & 8.3 \\
\hline $\mathrm{H} 2$ & 2013-06-15 & $20: 37: 31$ & 0.84300 & -28.2810 & 10.0 & 4.6 & 329.1 & 307.3 & 40.7 & 35.2 & 0.4 & 8.7 \\
\hline $\mathrm{H} 4$ & 2013-06-15 & $20: 37: 31$ & 0.84300 & -28.2810 & 10.0 & 4.6 & 423.7 & 402.4 & 54.7 & 49.7 & 0.3 & 8.1 \\
\hline H5 & 2013-06-15 & $20: 37: 31$ & 0.84300 & -28.2810 & 10.0 & 4.6 & 113.3 & 90.5 & 15.0 & 8.7 & 1.7 & 10.4 \\
\hline $\mathrm{H} 2$ & 2013-07-20 & $01: 59: 52$ & 1.96300 & -30.6500 & 10.0 & 4.7 & 104.4 & 82.6 & 15.0 & 9.5 & 1.4 & 8.7 \\
\hline $\mathrm{H} 4$ & 2013-07-20 & 01:59:52 & 1.96300 & -30.6500 & 10.0 & 4.7 & 690.1 & 668.8 & 95.0 & 90.0 & 0.1 & 7.4 \\
\hline $\mathrm{H} 5$ & 2013-07-20 & 01:59:52 & 1.96300 & -30.6500 & 10.0 & 4.7 & 376.1 & 353.3 & 55.0 & 48.7 & 0.3 & 7.3 \\
\hline $\mathrm{H} 2$ & 2013-07-20 & $12: 32: 49$ & 0.99600 & -30.5370 & 10.0 & 3.9 & 97.1 & 75.3 & 13.7 & 8.2 & 1.7 & 9.2 \\
\hline $\mathrm{H} 4$ & 2013-07-20 & $12: 32: 49$ & 0.99600 & -30.5370 & 10.0 & 3.9 & 659.2 & 637.9 & 85.0 & 80.0 & 0.2 & 8.0 \\
\hline H5 & 2013-07-20 & $12: 32: 49$ & 0.99600 & -30.5370 & 10.0 & 3.9 & 319.9 & 297.1 & 41.0 & 34.7 & 0.4 & 8.6 \\
\hline $\mathrm{H} 2$ & 2013-07-21 & $14: 54: 12$ & 1.94900 & -30.7340 & 10.0 & 3.9 & 96.5 & 74.7 & 13.6 & 8.1 & 1.7 & 9.2 \\
\hline $\mathrm{H} 4$ & 2013-07-21 & $14: 54: 12$ & 1.94900 & -30.7340 & 10.0 & 3.9 & 698.8 & 677.5 & 92.5 & 87.5 & 0.1 & 7.7 \\
\hline H5 & 2013-07-21 & $14: 54: 12$ & 1.94900 & -30.7340 & 10.0 & 3.9 & 383.3 & 360.5 & 51.0 & 44.7 & 0.3 & 8.1 \\
\hline
\end{tabular}




\begin{tabular}{|c|c|c|c|c|c|c|c|c|c|c|c|c|} 
H2 & $2013-07-25$ & $05: 13: 50$ & 1.86000 & -30.4620 & 10.0 & 3.5 & 114.4 & 92.6 & 16.0 & 10.5 & 1.3 & 8.8 \\
\hline H4 & $2013-07-25$ & $05: 13: 50$ & 1.86000 & -30.4620 & 10.0 & 3.5 & 666.0 & 644.7 & 91.0 & 86.0 & 0.1 & 7.5 \\
\hline H5 & $2013-07-25$ & $05: 13: 50$ & 1.86000 & -30.4620 & 10.0 & 3.5 & 352.3 & 329.5 & 49.5 & 43.2 & 0.3 & 7.6 \\
\hline H2 & $2013-08-09$ & $01: 26: 16$ & 3.03200 & -31.3160 & 12.0 & 4.8 & 188.3 & 166.5 & 27.5 & 22.0 & 0.6 & 7.6 \\
\hline H4 & $2013-08-09$ & $01: 26: 16$ & 3.03200 & -31.3160 & 12.0 & 4.8 & 796.9 & 775.6 & 109.5 & 104.5 & 0.1 & 7.4 \\
\hline H5 & $2013-08-09$ & $01: 26: 16$ & 3.03200 & -31.3160 & 12.0 & 4.8 & 505.3 & 482.5 & 70.3 & 64.0 & 0.2 & 7.5 \\
\hline
\end{tabular}




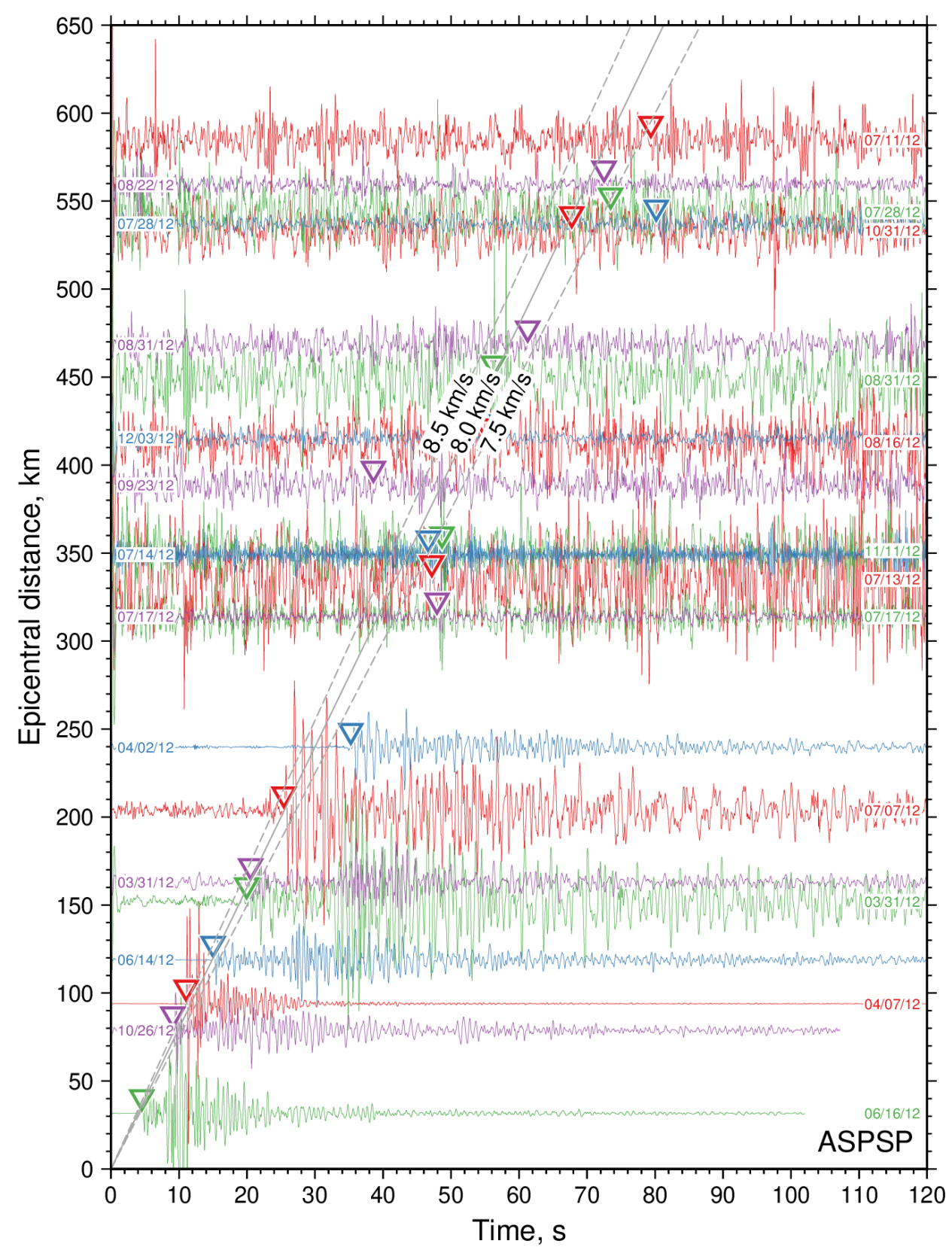

Figures S1. Common-receiver record section for seismograph ASPSP on St Peter and St Paul islets; waveforms plotted with a 4-12 Hz Butterworth filter, amplitudes scaled to minimize overlap between adjacent traces; dashed solid/dashed lines show range of likely $P n$ velocities; colored triangles are $P n$ arrival picks. 


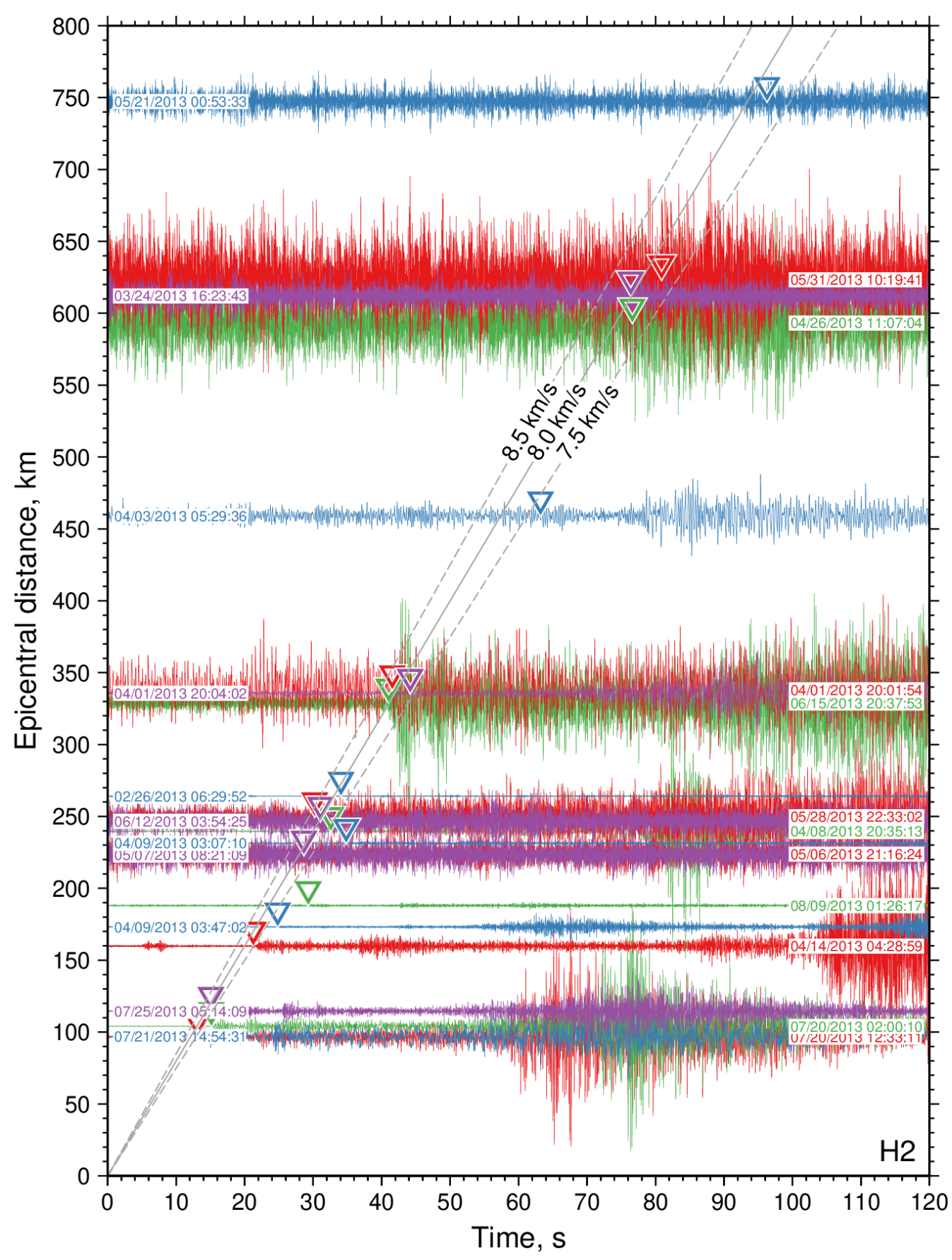

Figures S2. Common-receiver record sections for hydrophone H2; waveforms plotted with a 6$20 \mathrm{~Hz}$ Butterworth filter, amplitudes scaled to minimize overlap between adjacent traces; dashed solid/dashed lines show range of likely $P n$ velocities; colored triangles are $P n$ arrival picks. 


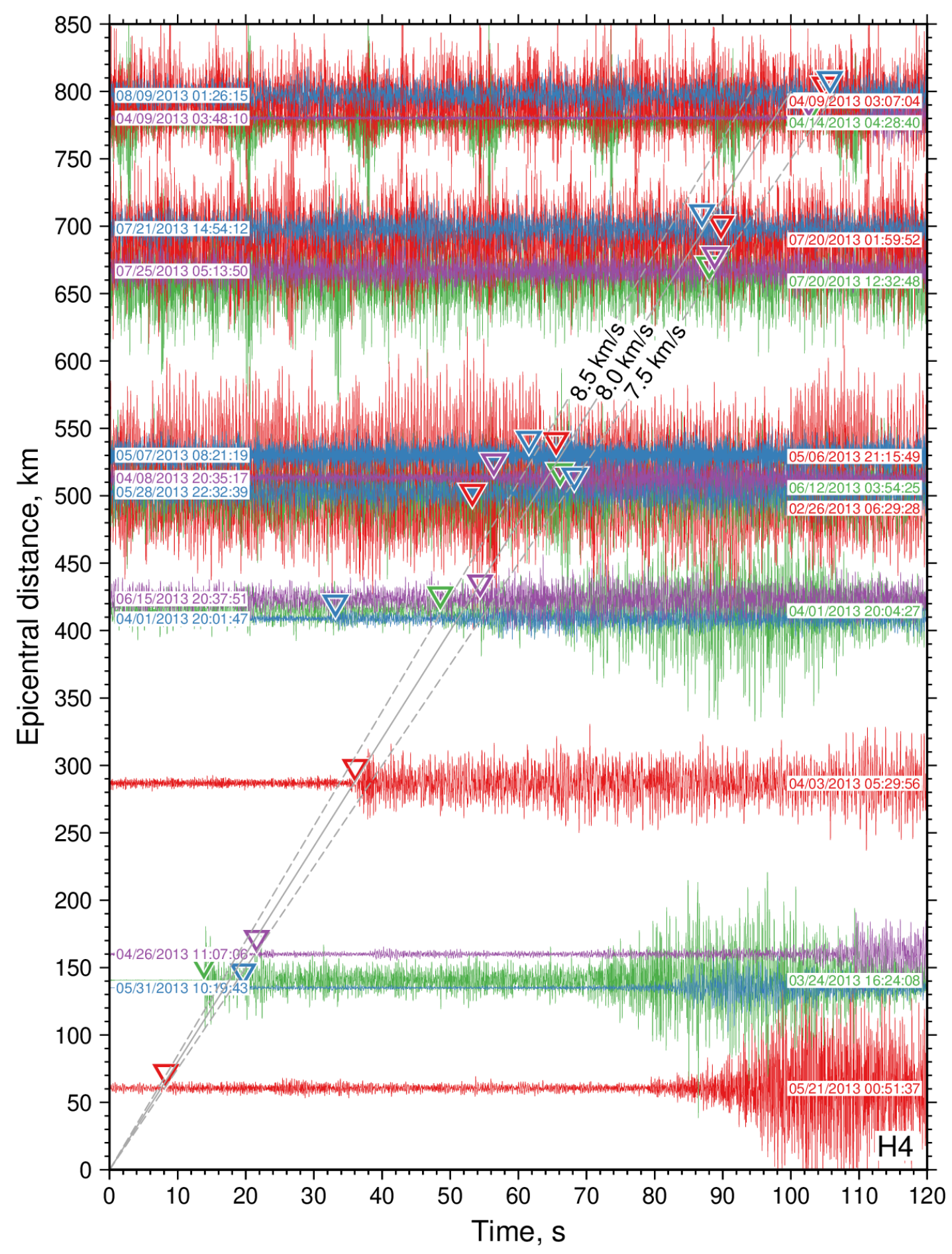

Figures S3. Common-receiver record sections for hydrophone H4; waveforms plotted with a 6$20 \mathrm{~Hz}$ Butterworth filter; amplitudes scaled to minimize overlap between adjacent traces; dashed solid/dashed lines show range of likely $P n$ velocities; colored triangles are $P n$ arrival picks. 


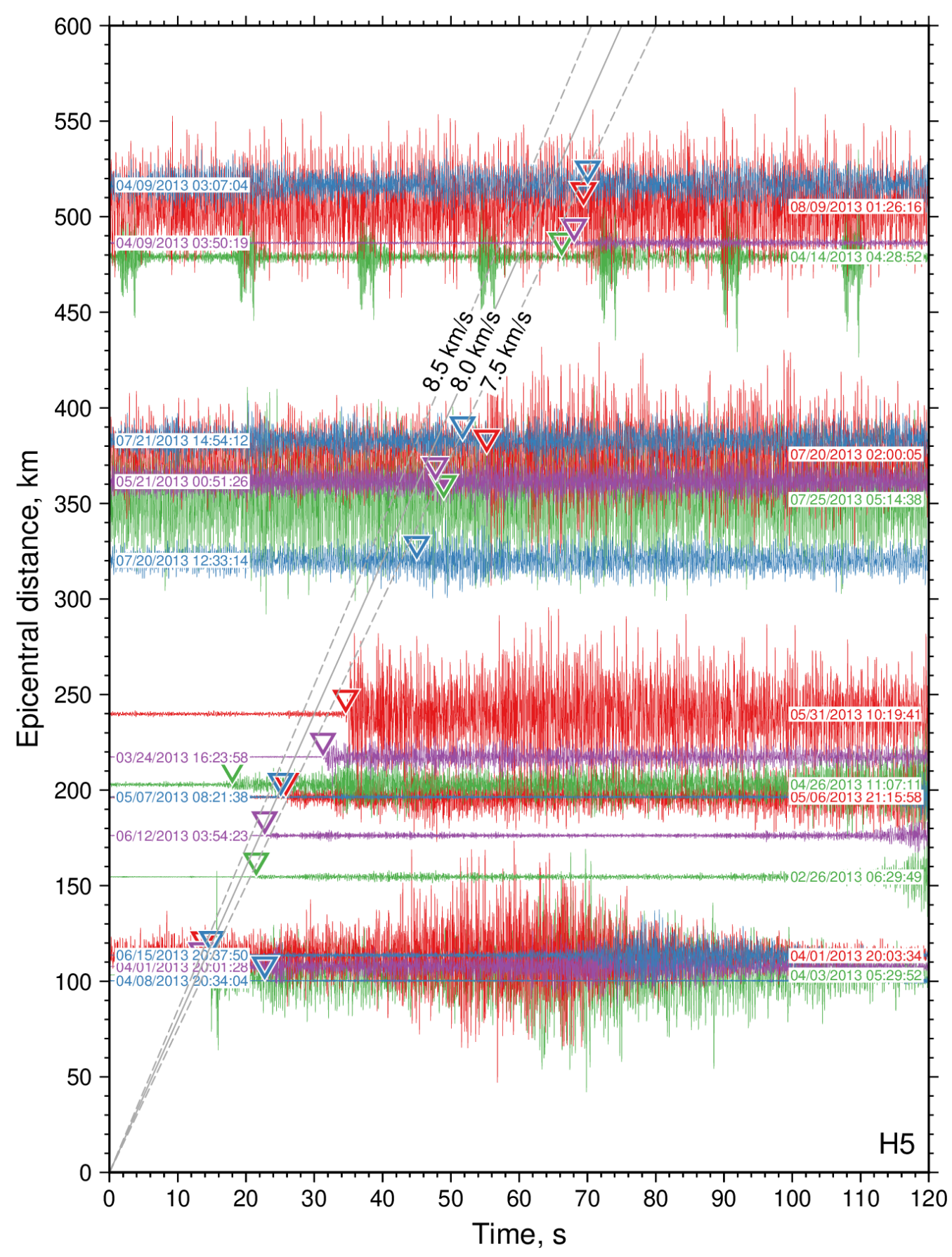

Figures S4. Common-receiver record section for hydrophone H5; waveforms plotted with a 6$20 \mathrm{~Hz}$ Butterworth filter, amplitudes scaled to minimize overlap between adjacent traces; dashed solid/dashed lines show range of likely $P n$ velocities; colored triangles are $P n$ arrival picks. 


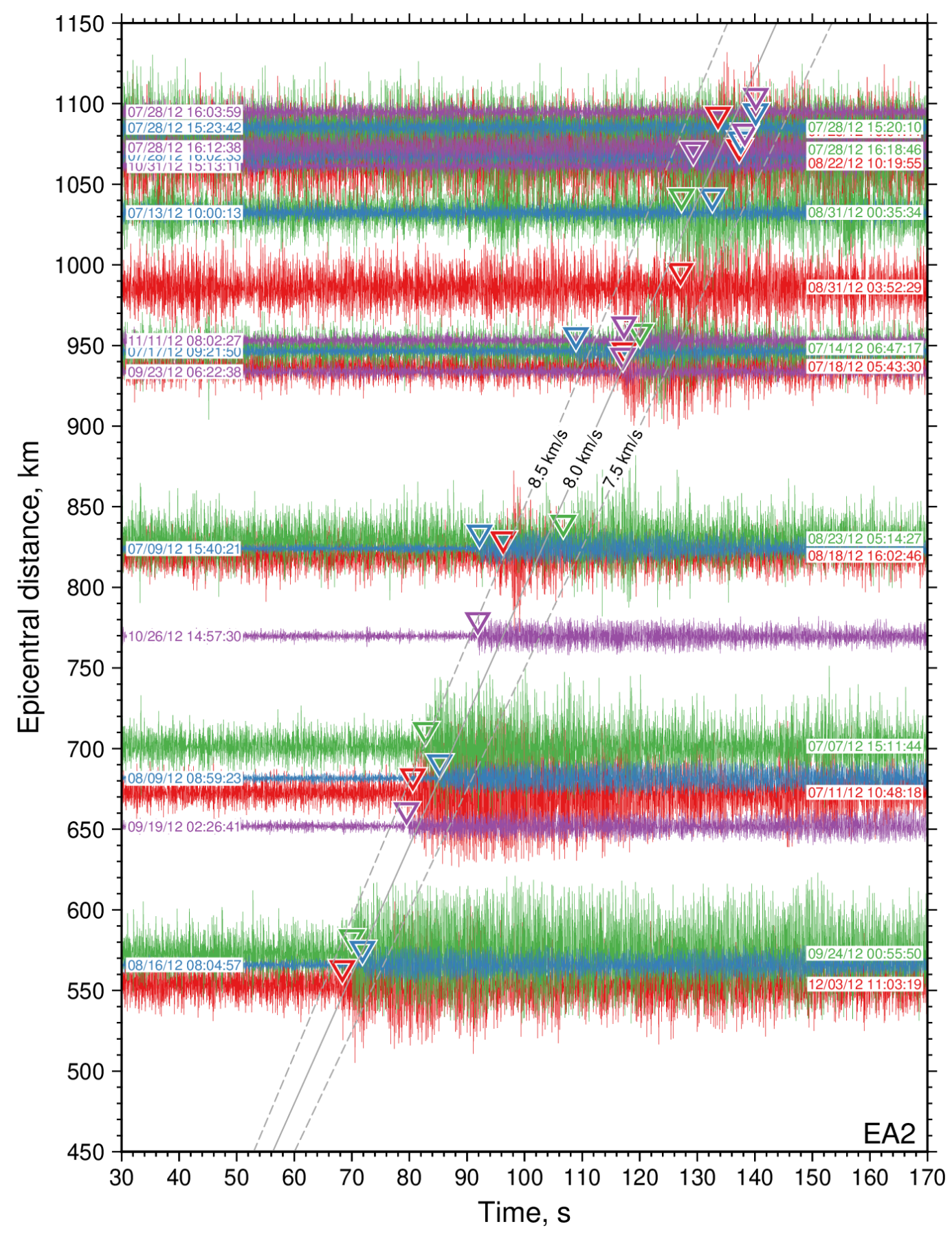

Figures S5. Common-receiver record section for hydrophone EA2; waveforms plotted with a 6$20 \mathrm{~Hz}$ Butterworth filter, amplitudes scaled to minimize overlap between adjacent traces; dashed solid/dashed lines show range of likely $P n$ velocities; colored triangles are $P n$ arrival picks. 


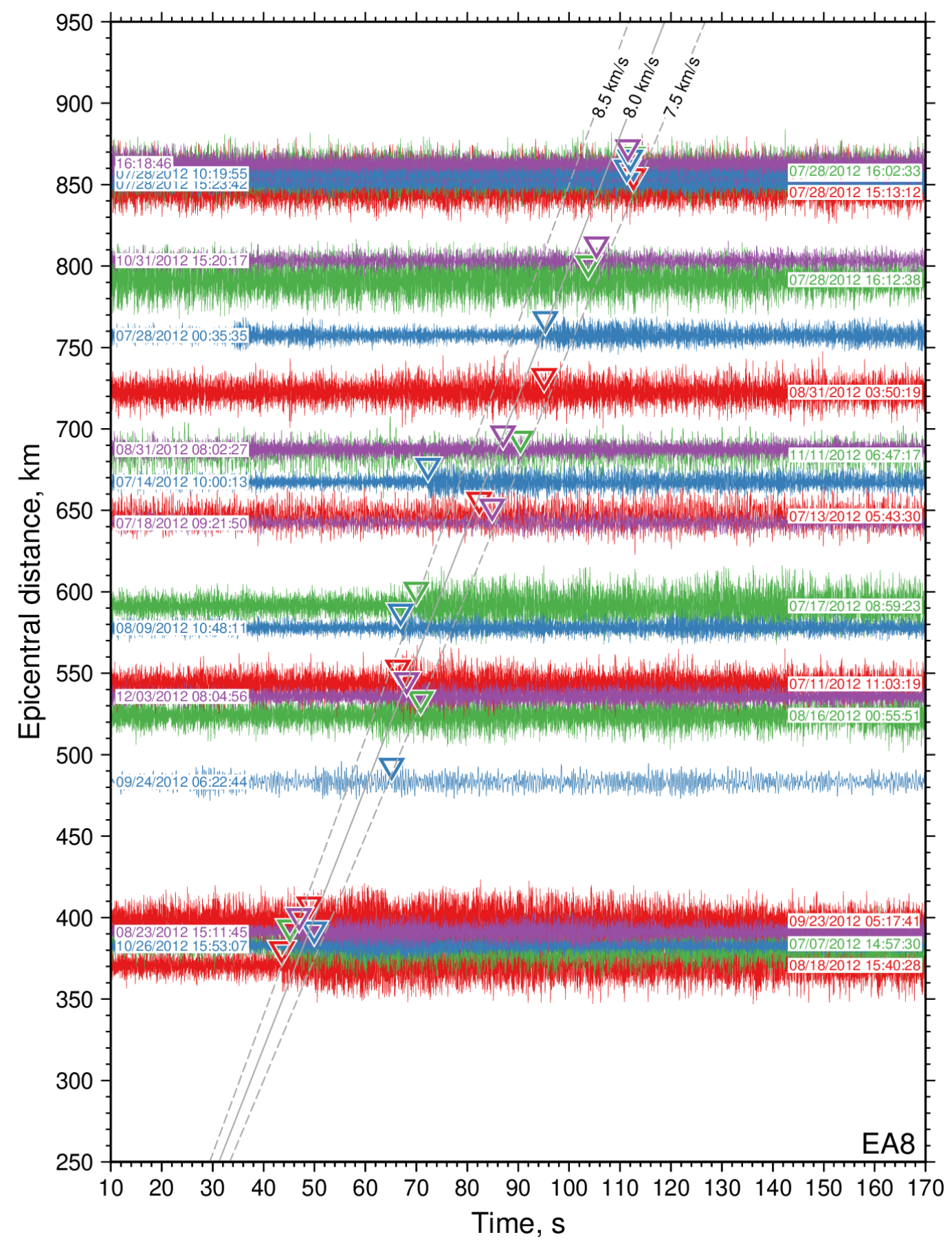

Figures S6. Common-receiver record section for hydrophone EA8; waveforms plotted with a 6$20 \mathrm{~Hz}$ Butterworth filter, amplitudes scaled to minimize overlap between adjacent traces; dashed solid/dashed lines show range of likely $P n$ velocities; colored triangles are $P n$ arrival picks. 
(a)
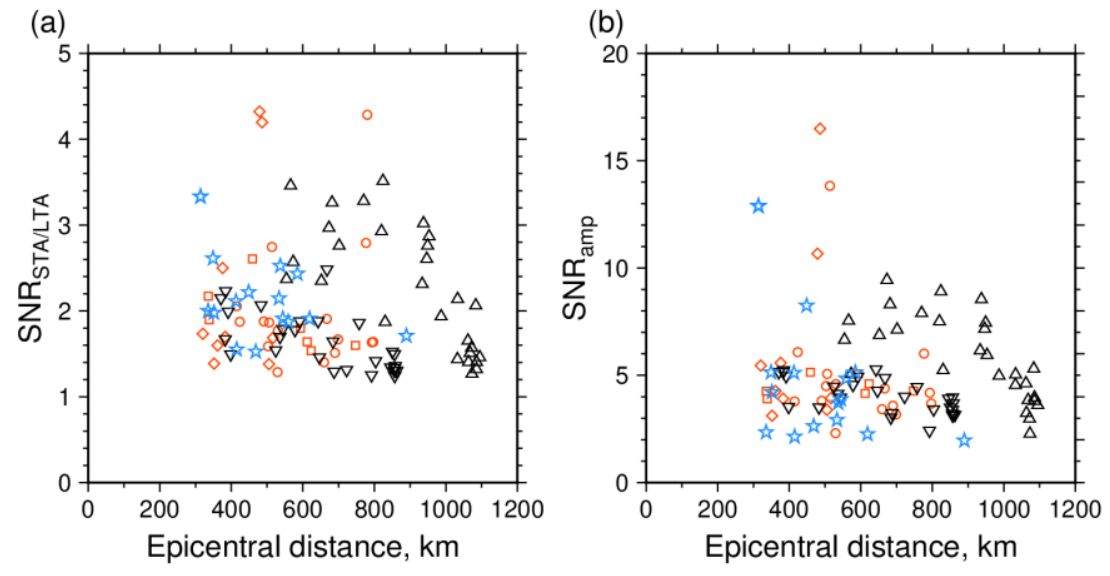

(c)

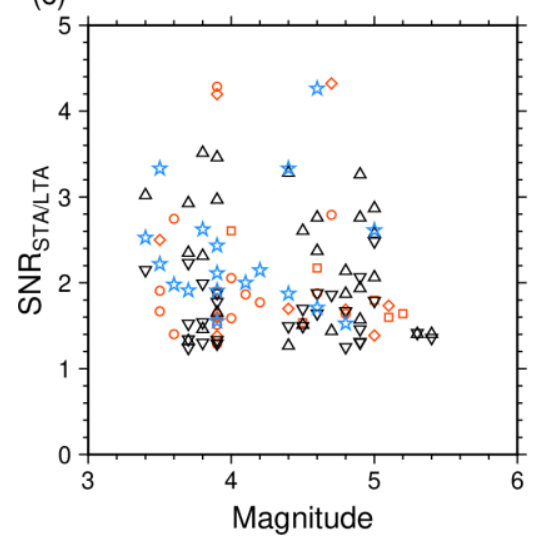

(d)

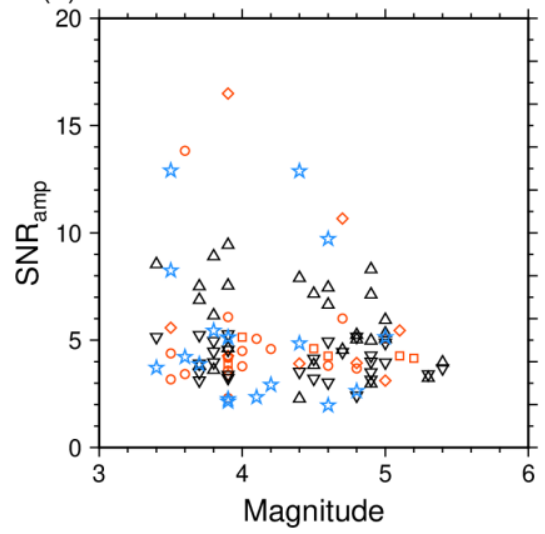

$\star$ ASPSP

$\boldsymbol{\nabla}$ EA8

$\Delta$ EA2

$\diamond \mathrm{H} 5$

○ $\mathrm{H} 4$

口 $\mathrm{H} 2$

Figure S7. Noise characterization of $P n$ arrivals. a) Signal to noise ratio estimated from the ratio between short time ( $1 \mathrm{~s}$ window) and long time (20 s window) average amplitudes (SNR STA/LTA $_{\text {), }}$ as a function of epicentral distance, key shows symbols used for stations. b) SNR estimated from ratio between the peak amplitude and the root mean square noise amplitude $\left(S N R_{a m p}\right)$, as a function of epicentral distance. c) $S N R_{S T A / L T A}$ as a function of magnitude. d) $S N R_{a m p}$ as a function of magnitude. e) $S N R_{S T A} / L T A$ vs. $S N R_{a m p}$, symbols with error bars are mean values of $S N R$ for each station \pm 1 standard deviation. 


\section{References}

de Melo, G., and A. F. do Nascimento (2018). Earthquake Magnitude Relationships for the Saint Peter and Saint Paul Archipelago, Equatorial Atlantic, Pure Appl. Geophys. 175, no. 3, 741756, doi: 10.1007/s00024-017-1732-6.

de Queiroz, D., A. F. do Nascimento, and M. Schimmel (2017). Microseismic noise in the Saint Peter and Saint Paul Archipelago, equatorial Atlantic, J. South Am. Earth Sci. 80, 304-315, doi: 10.1016/j.jsames.2017.09.035.

VanderBeek, B. P., and D. R. Toomey (2017). Shallow Mantle Anisotropy Beneath the Juan de Fuca Plate, Geophys. Res. Lett. 44, no. 22, 11,382-11,389, doi: 10.1002/2017GL074769. 


\section{Author mailing addresses}

Departamento de Geofisica, Federal University of Rio Grande do Norte, Natal, Brazil (GWSM, AFN)

Institute of Geophysics and Planetary Physics, Scripps Institution of Oceanography, University of California, San Diego, CA, USA

(RPT)

NOAA, Pacific Marine Environmental Laboratory, Newport, OR, USA (RPD)

National Science Foundation, Alexandria, VA, USA

(DKS)

Laboratoire Geosciences Ocean, CNRS and University of Brest

LGO-IUEM, rue Dumont Durville, 29280 Plouzane, France

(MM and JYR) 